\title{
Psychosocial interventions for the prevention of disability following traumatic physical injury (Review)
}

De Silva M, MacLachlan M, Devane D, Desmond D, Gallagher P, Schnyder U, Brennan M, Patel V

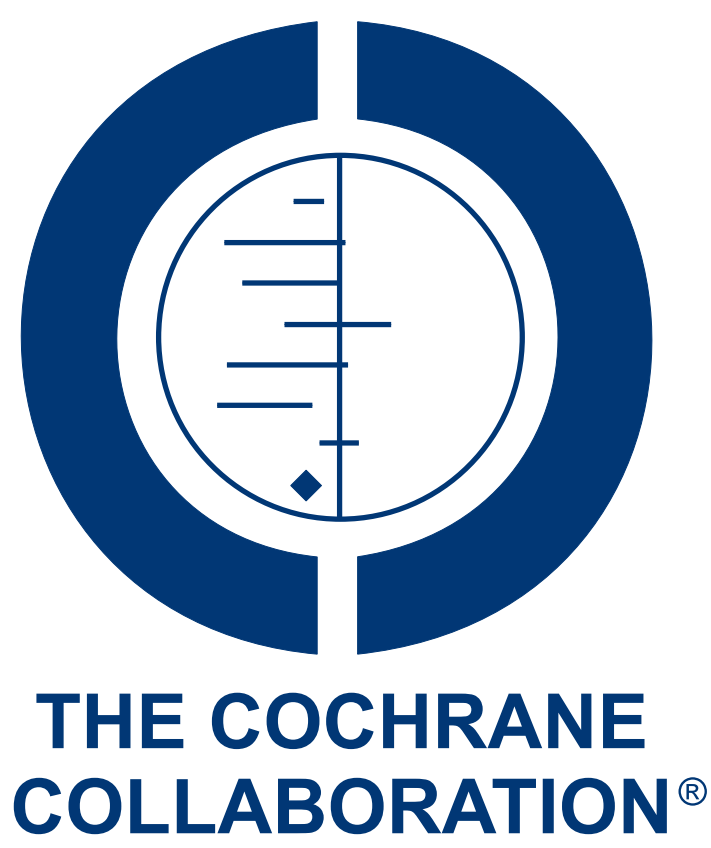

This is a reprint of a Cochrane review, prepared and maintained by The Cochrane Collaboration and published in The Cochrane Library 2009, Issue 4

http://www.thecochranelibrary.com

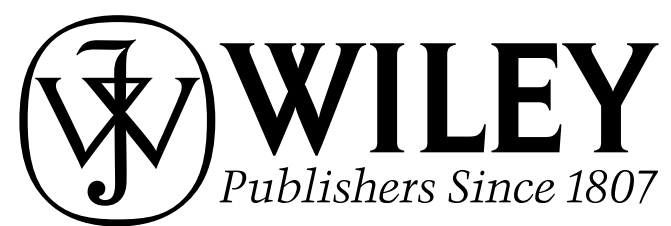

Psychosocial interventions for the prevention of disability following traumatic physical injury (Review)

Copyright (C) 2009 The Cochrane Collaboration. Published by John Wiley \& Sons, Ltd. 
TABLE OF CONTENTS

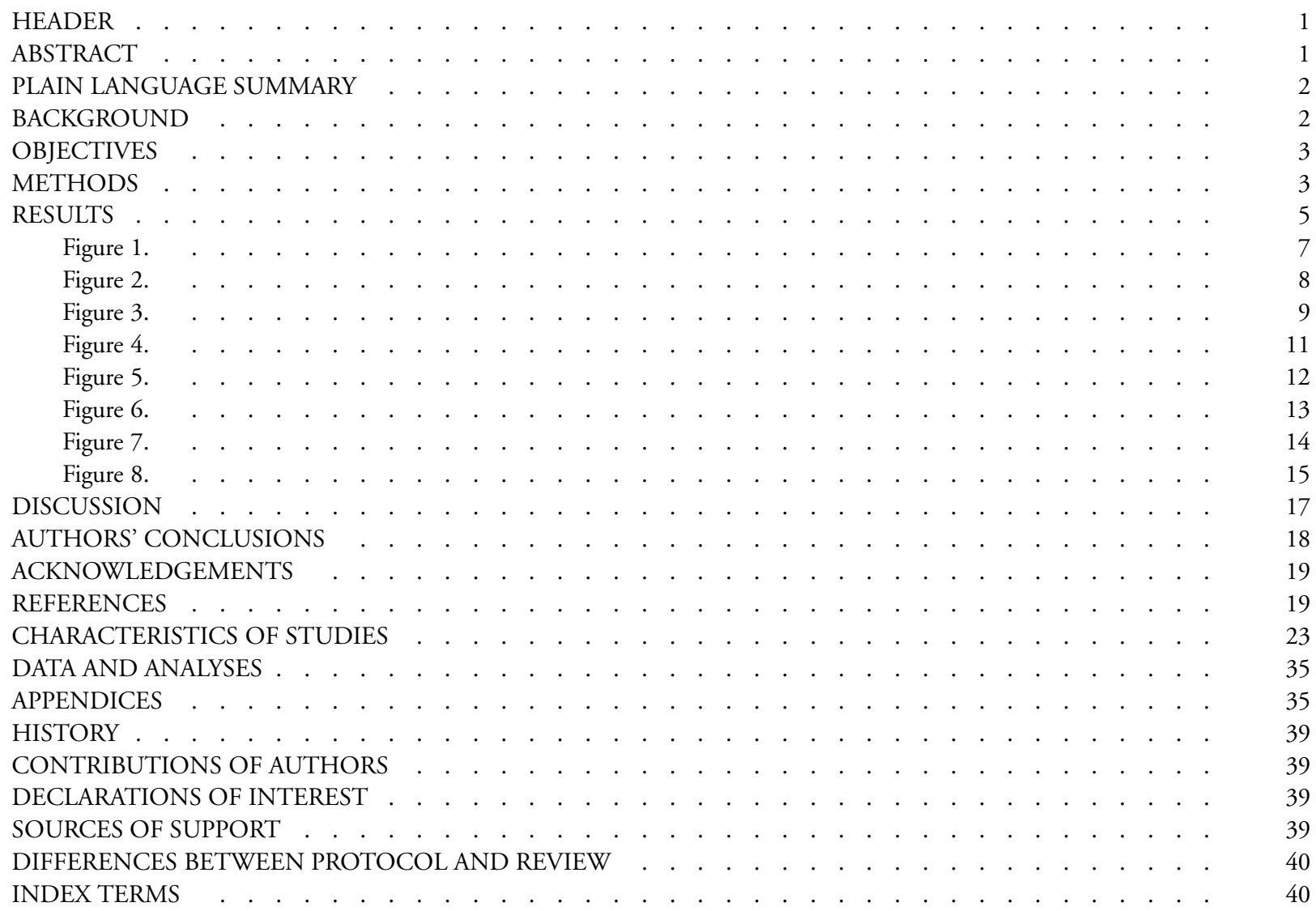




\title{
[Intervention Review]
}

\section{Psychosocial interventions for the prevention of disability following traumatic physical injury}

\author{
Mary De Silva ${ }^{2}$, Malcolm MacLachlan ${ }^{1}$, Declan Devane ${ }^{3}$, Deirdre Desmond ${ }^{4}$, Pamela Gallagher ${ }^{5}$, Ulrich Schnyder ${ }^{6}$, Muireann \\ Brennan $^{7}$, Vikram Patel ${ }^{2}$ \\ ${ }^{1}$ Centre for Global Health and School of Psychology, Trinity College, University of Dublin, Dublin, Ireland. ${ }^{2}$ Nutrition \& Public \\ Health Intervention Research Unit, London School of Hygiene \& Tropical Medicine, London, UK. ${ }^{3}$ School of Nursing and Midwifery, \\ National University of Ireland Galway, Galway, Ireland. ${ }^{4}$ Department of Psychology, National University of Ireland, Maynooth, Ireland. \\ ${ }^{5}$ School of Nursing, Dublin City University, Dublin, Ireland. ${ }^{6}$ Department of Psychiatry, University Hospital, Zurich, Switzerland. \\ ${ }^{7}$ International Emergency \& Refugee Health Branch, Centers for Disease Control and Prevention, Atlanta, GA, USA \\ Contact address: Malcolm MacLachlan, Centre for Global Health and School of Psychology, Trinity College, University of Dublin, \\ Dublin, Ireland. malcolm.maclachlan@tcd.ie.
}

Editorial group: Cochrane Injuries Group.

Publication status and date: New, published in Issue 4, 2009.

Review content assessed as up-to-date: 3 February 2008.

Citation: De Silva M, MacLachlan M, Devane D, Desmond D, Gallagher P, Schnyder U, Brennan M, Patel V. Psychosocial interventions for the prevention of disability following traumatic physical injury. Cochrane Database of Systematic Reviews 2009, Issue 4. Art. No.: CD006422. DOI: 10.1002/14651858.CD006422.pub3.

Copyright (C) 2009 The Cochrane Collaboration. Published by John Wiley \& Sons, Ltd.

\section{A B S T R A C T}

\section{Background}

Traumatic physical injury can result in many disabling sequelae including physical and mental health problems and impaired social functioning.

\section{Objectives}

To assess the effectiveness of psychosocial interventions in the prevention of physical, mental and social disability following traumatic physical injury.

\section{Search methods}

The search was not restricted by date, language or publication status. We searched the following electronic databases; Cochrane Injuries Group Specialised Register, CENTRAL (The Cochrane Library 2009, Issue 1), MEDLINE (Ovid SP), EMBASE (Ovid SP), PsycINFO (Ovid SP), Controlled Trials metaRegister (www.controlled-trials.com), AMED (Allied \& Complementary Medicine), ISI Web of Science: Social Sciences Citation Index (SSCI), PubMed. We also screened the reference lists of all selected papers and contacted authors of relevant studies. The latest search for trials was in February 2008.

\section{Selection criteria}

Randomised controlled trials that consider one or more defined psychosocial interventions for the prevention of physical disability, mental health problems or reduced social functioning as a result of traumatic physical injury. We excluded studies that included patients with traumatic brain injury (TBI).

\section{Data collection and analysis}

Two authors independently screened the titles and abstracts of search results, reviewed the full text of potentially relevant studies, independently assessed the risk of bias and extracted data. 


\section{Main results}

We included five studies, involving 756 participants. Three studies assessed the effect of brief psychological therapies, one assessed the impact of a self-help booklet, and one the effect of collaborative care. The disparate nature of the trials covering different patient populations, interventions and outcomes meant that it was not possible to pool data meaningfully across studies. There was no evidence of a protective effect of brief psychological therapy or educational booklets on preventing disability. There was evidence from one trial of a reduction in both post-traumatic stress disorder (PTSD) and depressive symptoms one month after injury in those who received a collaborative care intervention combined with a brief psycho-educational intervention, however this was not retained at follow up. Overall mental health status was the only disability outcome affected by any intervention. In three trials the psychosocial intervention had a detrimental effect on the mental health status of patients.

\section{Authors' conclusions}

This review provides no convincing evidence of the effectiveness of psychosocial interventions for the prevention of disability following traumatic physical injury. Taken together, our findings cannot be considered as supporting the provision of psychosocial interventions to prevent aspects of disability arising from physical injury. However, these conclusions are based on a small number of disparate trials with small to moderate sample sizes and are therefore necessarily cautious. More research, using larger sample sizes, and similar interventions and patient populations to enable pooling of results, is needed before these findings can be confirmed.

\section{PLAIN LANGUAGE SUMMARY}

\section{Psychosocial interventions for the prevention of disability following traumatic physical injury}

Traumatic physical injury such as that resulting from road traffic accidents, falls and fires can cause high levels of subsequent disability in the person affected. This may include physical disability as a result of the initial injury and subsequent complications, mental health problems such as depression, anxiety and post-traumatic stress disorder (PTSD) as a result of the trauma of the event which caused the injury and the resulting physical and social problems, and social problems such as loss of social life and unemployment. It is therefore important to evaluate interventions which seek to prevent these adverse secondary outcomes. Psychosocial interventions, which include psychological therapies such as interpersonal counselling and cognitive behavioural therapy (CBT), and social interventions such as befriending, social support and self-help advice, delivered soon after the injury, may help to prevent these problems.

This review identified five randomised controlled trials, involving 756 participants, which evaluated psychosocial interventions for the prevention of disability following traumatic injury. No convincing evidence was found supporting the efficacy of these interventions. In particular, self-help booklets and interpersonal therapies had no effect on preventing disability. There was some evidence that a more complex intervention involving collaborative care reduced symptoms of depression and PTSD in the short but not the medium term. There was evidence from three trials that psychosocial interventions had a detrimental effect on mental health. Taken together, our findings cannot be taken as supporting the provision of psychosocial interventions to prevent aspects of disability arising from physical injury. These results suggest that future interventions should focus on screening patients at risk of poor outcomes and only treating those who develop subsequent problems. However, the strength of these conclusions is limited by the small size and varied nature of many of the trials, which means that their results cannot be pooled.

\section{B A C K G R O U N D}

\section{Description of the condition}

Injuries account for $9 \%$ of the world's deaths and $12 \%$ of the world's disease burden (WHO 2002), and may arise from road traffic crashes, poisoning, falls, fires, drowning, interpersonal vio- lence and war, self-inflicted injuries, as well as other sources. The World Health Organization (WHO) states that "while mortality is an important indicator of the magnitude of a health problem, it is important to realise that for each injury death, there are several thousand injury survivors who are left with permanent disabling sequelae" (WHO 2002, p 3). Even in patients with physical prob- 
lems that do not arise from traumatic injury, the ability to function effectively is strongly influenced by factors such as mood, coping skills and social support. Interventions that influence these factors are therefore likely to contribute to better health and more costeffective outcomes (Sobel 1995).

Schnyder et al found that $25.5 \%$ of severely injured accident victims showed some form of psychiatric morbidity after one year and that this "can be predicted to some degree by mainly psychosocial variables" (Schnyder 2001, p 653), in particular patients' early cognitive appraisal of their accident. However, while NICE (Gersons 2005) has endorsed the effectiveness of longer-term psychosocial interventions in the aftermath of psychological trauma, the effectiveness of short-term 'debriefing' has not been demonstrated (Rose 2002). While psychosocial interventions following physical injury may alleviate psychiatric co-morbidity, we wish to focus on the benefits of preventive interventions rather than therapeutic interventions per se. To date, there has been no attempt to systematically review the effects of psychosocial interventions that seek to alleviate the distress of those who have acquired physical injuries, including subsequent disability. This review will provide this evidence. For the purposes of this review, by disability we mean any diminution in an individual's psychological, social or physical functioning that has arisen following, and as a consequence of, a traumatic physical injury.

\section{Description of the intervention}

This review will focus on primary preventive rather than therapeutic interventions, as intervening early after the traumatic event to a general population of trauma patients presents a novel approach to the reduction of disability following traumatic injury. Psychosocial interventions are interventions that have their primary mode of action through psychological or social processes. Such interventions include, for instance, direct therapeutic work, health education and social support.

\section{How the intervention might work}

Physical injury may result in impairment of physical functioning. The way in which people respond to such impairment, along with the social and environmental context they live in, determines the degree of disability associated with the injury. A physical injury may disable people in terms of their physical, mental or social functioning. An individual's own ability to cope with physical impairment, as well as their broader social situation, offers opportunities to reduce the extent to which physical injury results in disability. By providing people with psychological and social resources that assist their coping responses to physical impairment, psychosocial interventions may be able to prevent physical impairment resulting in physical, mental and social disability.

\section{Why it is important to do this review}

This is the first systematic review to consider the effectiveness of psychosocial interventions designed to prevent disability following an injury that produces physical impairment.

\section{O B J E C T I VES}

\section{Primary objective}

- To assess the effectiveness of psychosocial interventions in the prevention of physical, mental and social disability following traumatic physical injury (excluding traumatic brain injury (TBI)), when compared to usual care or other experimental intervention.

\section{Secondary objectives}

- To assess the effectiveness of different types of psychosocial interventions.

- To assess the effectiveness of psychosocial interventions on different post-injury outcomes (physical disability, mental health and social functioning).

\section{METHODS}

\section{Criteria for considering studies for this review}

\section{Types of studies}

Randomised controlled trials that considered one or more defined psychosocial interventions for the prevention of physical disability, mental health problems or reduced social functioning as a result of traumatic physical injury. We included cross-over trials, clusterrandomised trials and factorial trials.

We excluded non-randomised intervention studies.

\section{Types of participants}

Patients who have suffered a traumatic physical injury.

We excluded trials which included people with traumatic brain injury (TBI) unless they could be disaggregated from other physically injured people who received the intervention, or comprised less than $20 \%$ of trial participants. We excluded trials which included people without traumatic physical injury (for example, psychological de-briefing following a traumatic incident not resulting in physical injury) if the results could not be disaggregated to 
include only those who had suffered a traumatic physical injury or those without physical injury comprise less than $20 \%$ of trial participants. We retrieved the full text of trials including patients with TBI or without traumatic physical injury and only excluded trials if the above conditions were not met. We excluded musculoskeletal conditions incurred other than through a physical injury. We only included sexual assault if it resulted in a physical injury.

\section{Types of interventions}

We define 'psychosocial interventions' as being any intervention that focuses on psychological and/or social factors rather than biological factors (definition taken from Ruddy 2005). This may include, but is not limited to:

- psychological therapies such as cognitive behavioural therapy (CBT), interpersonal psychotherapy, non-directive counselling, psychological debriefing and problem-solving therapy;

- social interventions such as befriending, mentoring and social support.

We included psychosocial interventions as long as they were sufficiently described by trialists to facilitate replication. Interventions may be administered by any health professional (for example, psychologist, medical practitioner, nurse or occupational therapist) or lay person and in any form, for example, individual or group therapy, over the telephone, or in the form of written material. Psychosocial interventions may be offered to enhance a person's coping resources without any suggestion that they are currently suffering through any type of psychopathology or psychological disorder. Such interventions may prevent circumstances arising where their ability to cope is exceeded, resulting in a state of psychological disorder or variously defined psychopathologies. It may well be the case that people who are currently experiencing psychological disorder benefit from interventions designed to be preventive, and in this sense they may be understood as being therapeutic. However, our focus here is on prevention and not treatment.

Psychosocial interventions were compared with:

- usual care;

- pharmacological interventions, for example, treatments for mental health problems and pain relief;

- physical interventions, for example physiotherapy, provision of prosthetic devices or surgery;

- any mix of the above.

Trials were excluded if:

- the primary basis of action of the intervention is physical, such as pharmacological or physical interventions (for example, drug treatments, assistive technology, physiotherapy, or acupuncture);
- the primary basis of action of the intervention is economic (for example, direct cash transfers to pay for assistive technology or work-related training courses);

- the intervention is complex and includes pharmacological, physical and/or financial components as well as a psychosocial component and the results of the psychosocial component can not be disaggregated;

- the intervention is aimed solely at the treatment rather than the prevention of physical disability, mental health problems or social problems resulting from traumatic physical injury, for example the treatment of depression or post-traumatic stress disorder following physical injury amongst people post-injury who also have developed a mental illness;

- participants have been selected on the basis of poor mental health status;

- the intervention takes place more than 12 months after the traumatic injury as these trials will be dealing with the treatment rather than prevention of physical, mental and social sequelae;

- the intervention is designed to be therapeutic rather than preventative;

- the intervention is received by people with TBI unless they can be disaggregated from other physically injured people or constitute less than $20 \%$ of trial participants.

\section{Types of outcome measures}

\section{Primary outcomes}

- Physical disability such as extent of disability, measured using validated instruments.

- Mental health status measured using validated instruments or through structured mental state assessment.

- Global assessment of functioning, including quality of life and physical and social functioning, measured using validated instruments.

\section{Secondary outcomes}

- Social functioning, including social participation and employment status.

- Health care utilisation.

\section{Search methods for identification of studies}

The search was not restricted by date, language or publication status.

\section{Electronic searches}

We searched the following electronic databases; 
- Cochrane Injuries Group Specialised Register (searched 5 Feb 2008),

- CENTRAL (The Cochrane Library 2009, Issue 1),

- MEDLINE (Ovid SP) 1950 to Jan (week 5) 2008,

- EMBASE (Ovid SP) 1980 to (week 5) Jan 2008,

- PsycINFO (Ovid SP) 1806 to Jan (week 5) 2008,

- Controlled Trials metaRegister (www.controlled-trials.com) (Searched 5 Feb 2008),

- AMED (Allied \& Complementary Medicine) (1985 to 6 Feb 2008),

- ISI Web of Science: Social Sciences Citation Index (SSCI) 1970 to Feb 2008,

- PubMed [www.ncbi.nlm.nih.gov/sites/entrez/] (searched from 2006 to Feb 2008)

Full details of the search strategies can be found in Appendix 1 .

\section{Searching other resources}

We scanned the reference lists of all selected papers and contacted authors of relevant studies to seek out additional studies.

\section{Data collection and analysis}

\section{Selection of studies}

The Cochrane Injuries Group's Trials Search Co-ordinator ran the relevant search strategies across the appropriate databases. Two authors (MDS and MM) separately screened the titles and abstracts of the citations identified by the search to determine which papers met the pre-determined criteria. In case of doubt or disagreement, we obtained the full article for inspection. Full text copies of all potentially relevant studies were obtained and independently assessed by MDS and MM to determine whether they met the inclusion criteria. In the event of a disagreement, the third author (DD) was asked to give his opinion to resolve the issue. We stored all identified study records using electronic bibliographic software (Endnote XI)

\section{Data extraction and management}

Two authors (MDS and MM) extracted data from the trial reports using a purposefully designed data extraction form. In the event of a disagreement, the third author (DD) was asked to give his opinion. We contacted trial authors for missing data where appropriate.

\section{Assessment of risk of bias in included studies}

Two authors (MDS and MM) independently assessed the methodological quality of selected trials. In the event of a disagreement, the third author (DD) was consulted.
We used the 'Risk of bias' tool to assess the risk that a study overor under-estimates the true intervention effect. This tool involves a description and a judgement for the following criteria: sequence generation; allocation sequence concealment; blinding of outcome assessment; incomplete outcome data; selective outcome reporting; intention-to-treat analyses and other potential sources of bias. Each criterion was judged 'Yes' indicating low risk of bias, 'No' indicating high risk of bias, or 'Unclear' indicating either lack of information or uncertainty over the potential for bias. Plots of 'Risk of bias' assessments were created in Review Manager. We assessed missing data and attrition rates for each of the included studies, and reported the number of participants who were included in the final analysis as a proportion of all participants in the study. Reasons given for missing data are provided in the narrative summary. We ascertained the extent to which the results were altered by missing data. This qualitative quality assessment was not used as a threshold for inclusion of studies, but as a possible explanation for differences between studies when interpreting the results of the review (Schulz 1995).

\section{Dealing with missing data}

We contacted authors of all studies included in the review in order to obtain information absent from the published reports.

\section{Data synthesis}

As the studies were too disparate to allow pooling of results in a meta-analysis, we described the results of the trials using a qualitative summary. We performed no subgroup or sensitivity analyses.

\section{R E S U L T S}

\section{Description of studies}

See: Characteristics of included studies; Characteristics of excluded studies; Characteristics of studies awaiting classification.

\section{Results of the search}

The search strategy generated 1420 citations; 1417 from database searching, two from searching reference lists and one from contacting authors. MDS and MM independently checked the titles and abstracts of these citations and excluded 1350 as clearly irrelevant. We identified 70 citations as potentially relevant and located these for full text screening. We were unable to locate the full text of two studies (see 'Characteristics of studies awaiting classification'), and one study only had unpublished data. MDS and MM independently screened the full text of 67 studies. Sixtytwo were excluded as they did not meet the inclusion criteria (see 
'Characteristics of excluded studies'). Seventeen were not RCTs, 17 evaluated interventions for the treatment rather than prevention of disability, 11 evaluated a complex intervention for which the psychosocial component could not be disaggregated, seven did not measure an aspect of disability as the outcome of the trial, eight included more than $20 \%$ of patients who had not suffered a traumatic physical injury and two did not evaluate a psychosocial intervention. In total five studies met the inclusion criteria and were included in the review.
There were no disagreements which could not be resolved between MM and MDS when screening abstracts and titles, and two disagreements when screening the full text of reports. These were referred to DD for a third opinion and in both cases the studies were excluded. The kappa score for inter-rater reliability on a sample of 413 citations was 0.94 .

We made a flowchart of the process of trial selection in accordance with the QUORUM statement (Moher 1999) see Figure 1. 
Figure I. Selection process of eligible randomised controlled trials from all identified citations.

1420 citations identified from electronic databases and reference searching.

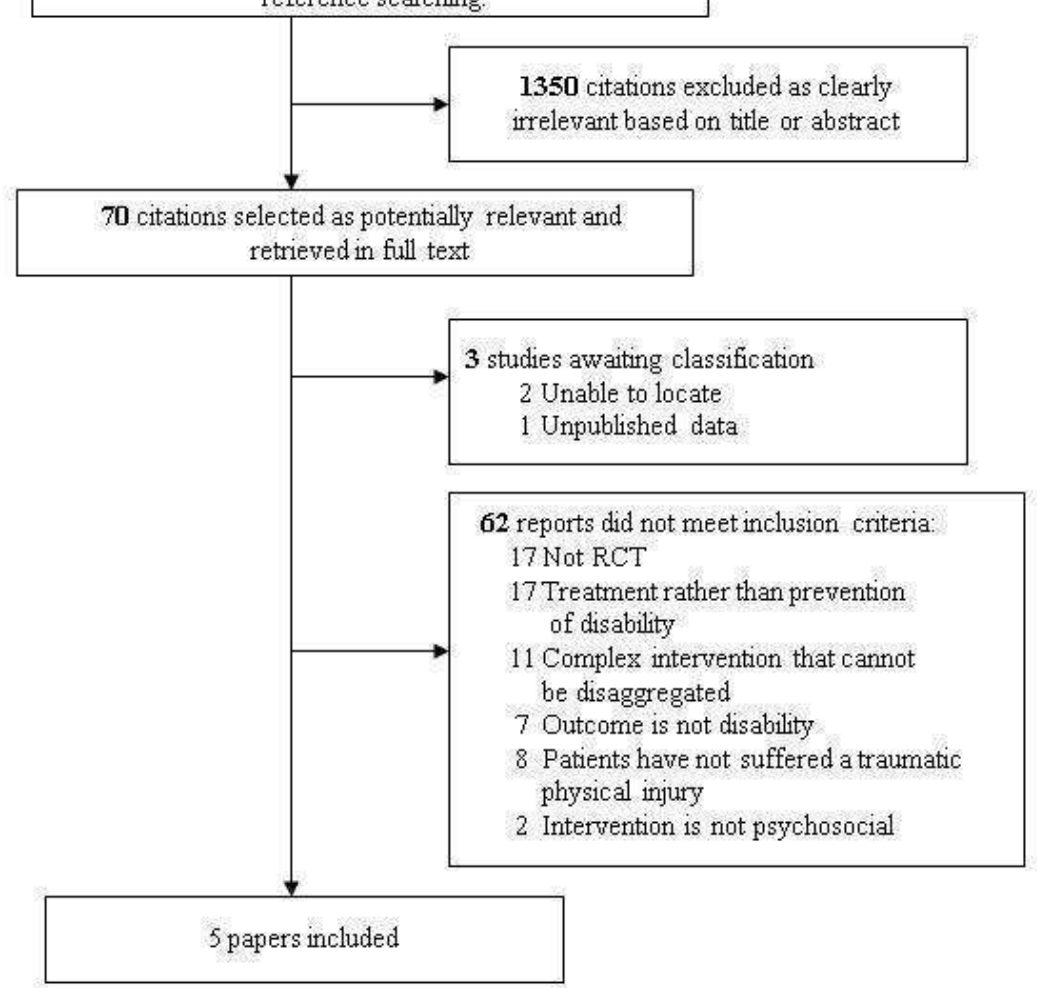




\section{Included studies}

See: 'Characteristics of included studies'; 'Characteristics of excluded studies'.

Five trials, involving 756 participants, are included in this review. The included trials were very different in terms of population studied, intervention assessed and outcomes. As such, pooling the results in a meta-analysis was not possible. Instead, studies are discussed according to intervention type.

Four trials included patients admitted to a trauma centre following a traumatic physical injury (Holmes 2007; Pirente 2007; Turpin 2005; Zatzick 2001) and one included patients who had undergone surgery for hip fracture (Burns 2007).

The eight included studies examined the following group comparisons:

1. CBT versus treatment as usual (Burns 2007; Pirente 2007);

2. interpersonal counselling versus treatment as usual (Holmes 2007);

3. collaborative care with a personally assigned trauma support specialist versus treatment as usual (Zatzick 2001);

4. self-help information booklet versus a letter without the booklet (Turpin 2005).
All but one study measured physical disability outcomes (Turpin 2005), and all included at least one mental health status outcome. Only one study assessed social functioning or health care utilisation (Burns 2007).

In total the five trials assessed 12 different outcomes. Four measured physical disability (mobility, pain and changes in pain, physical illness and physical functioning); six measured mental health status (depression and change in depressive symptoms, anxiety, PTSD and change in PTSD symptoms, alcohol abuse, substance abuse and any psychological disorder); one assessed global assessment of functioning (health related quality of life); and one assessed social functioning and health care use (length of stay in hospital). With the exception of depression, where two studies used the same tool, each study used a different tool to measure the outcomes.

\section{Risk of bias in included studies}

Where it was possible to assess this, included trials had generally poor ratings of trial quality and many suffered from biases in addition to those assessed by the Cochrane criteria (see Figure 2 and Figure 3).

Figure 2. Methodological quality graph: review authors' judgements about each methodological quality item presented as percentages across all included studies.

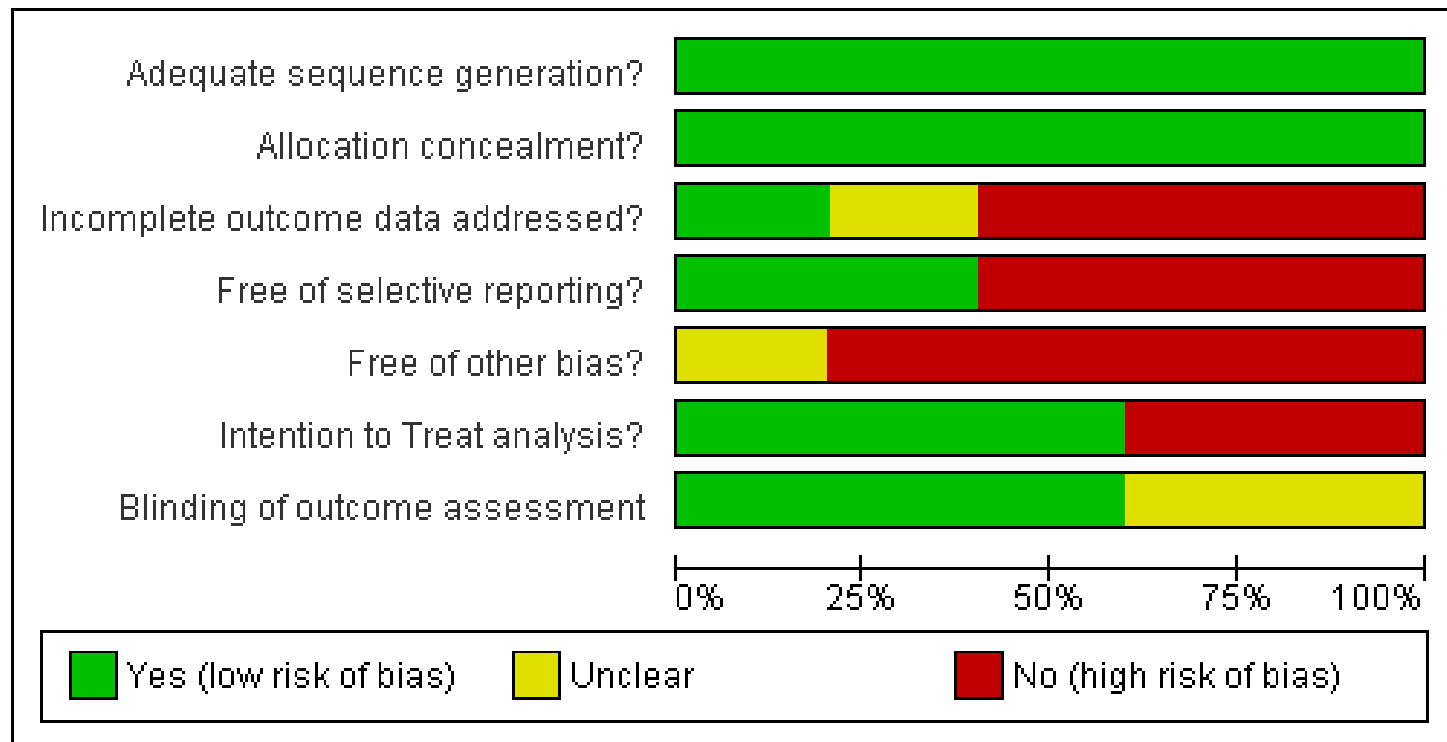

Psychosocial interventions for the prevention of disability following traumatic physical injury (Review) 
Figure 3. Methodological quality summary: review authors' judgements about each methodological quality item for each included study.

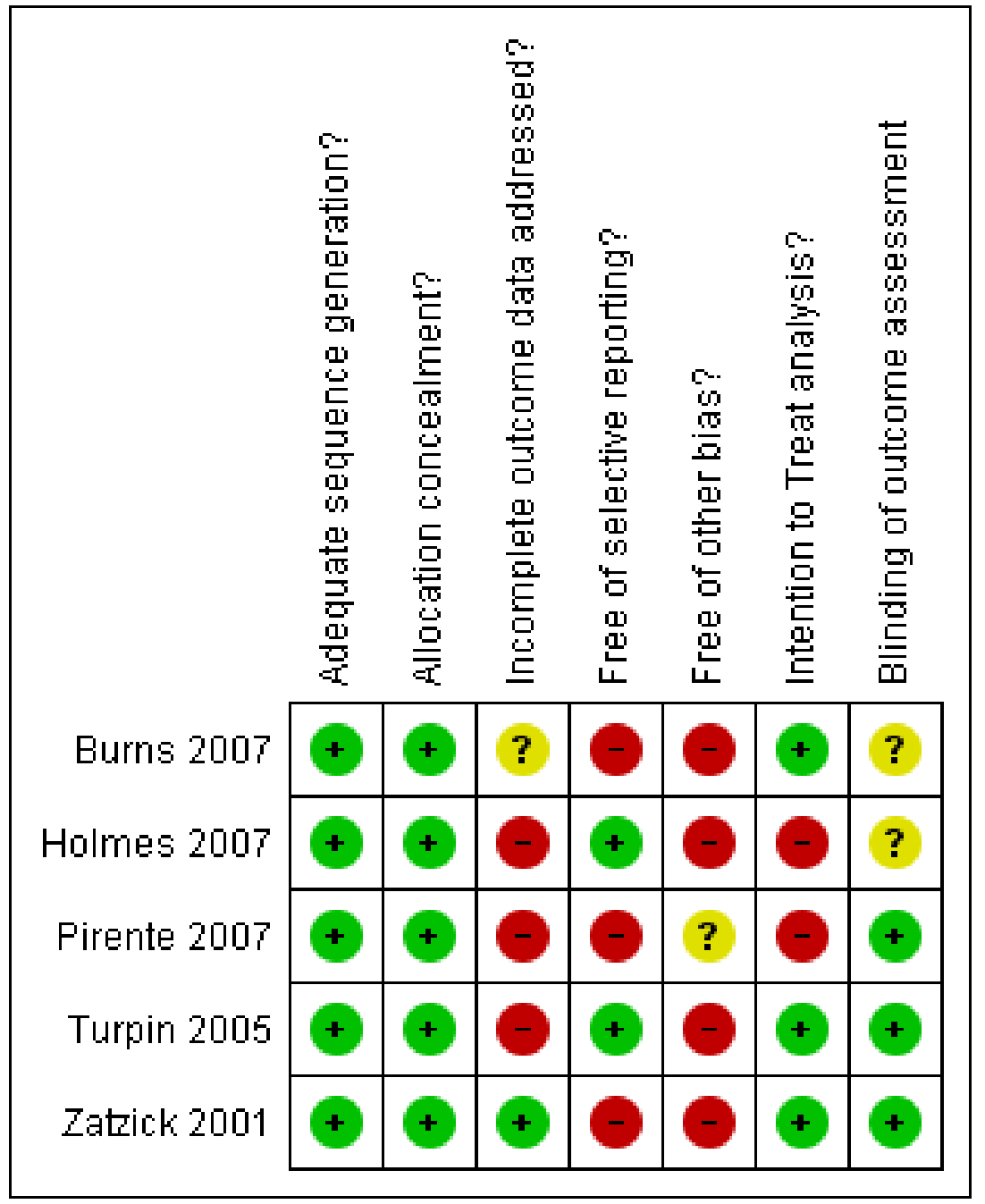

\section{Allocation}

All trials had adequate sequence generation, using computer generated randomisation or random number tables. All trials also had adequate allocation concealment, using either an independent telephone randomisation service or sealed opaque envelopes.

\section{Incomplete outcome data}

Only one trial adequately addressed incomplete outcome data with the reasons for losses to follow up clearly stated (Zatzick 2001). Two trials had less than 60\% follow up (Pirente 2007; Turpin 2005).

\section{Selective reporting}

Selective reporting of results occurred in all but two of the trial reports (Holmes 2007; Turpin 2005), with many not reporting all pre-specified outcomes or insignificant effect estimates. 


\section{Other potential sources of bias}

Only three trials performed intention-to-treat analyses. Significant other potential sources of bias included the small sample size (especially after high losses to follow up) and therefore lack of power for some studies.

\section{Effects of interventions}

We did not pool data due to heterogeneity between trials in terms of the intervention, outcomes, time point at which the outcome was assessed and the population studied. Instead, trials' results are discussed by intervention type (brief psychological therapies, self-help information and collaborative care). In addition, we performed no subgroup or sensitivity analyses due to the heterogeneity of the included studies. See Figure 4, Figure 5, Figure 6, Figure 7 and Figure 8 for full results of the included studies. 
Figure 4. Brief psychological therapy.

Table of results: disability review

Table 1: Brief psychological therapy

\begin{tabular}{|c|c|c|c|}
\hline \multicolumn{4}{|l|}{ Burns 2007} \\
\hline Participants & \multicolumn{3}{|c|}{$\begin{array}{l}170 \text { patients over } 60 \text { years old who have undergone surgery for hip } \\
\text { fracture in the previous } 2 \text { weeks and who were not depressed (scored } 6 \\
\text { or less on the Geriatric Depression Scale). }\end{array}$} \\
\hline Intervention & \multicolumn{3}{|c|}{ Up to 7 sessions of individual CBT. } \\
\hline Control & \multicolumn{3}{|l|}{ Treatment as usual. } \\
\hline Summary of results & \multicolumn{3}{|c|}{$\begin{array}{l}\text { No significant difference in the rate of depression, pain, mobility or } \\
\text { physical illiness between the intervention and treatment as usual groups, } \\
\text { at any time point. }\end{array}$} \\
\hline \multirow[t]{2}{*}{ Follow up } & \multicolumn{3}{|c|}{ n } \\
\hline & Intervention & Control & Total $(\%$ analysed $)$ \\
\hline Baseline & \multirow{4}{*}{$\begin{array}{l}85 \\
71 \\
62 \\
59\end{array}$} & 85 & 170 \\
\hline 6 weeks & & 64 & $135(79.4)$ \\
\hline 3 months & & 51 & $113(66.5)$ \\
\hline 6 months & & 51 & $110(64.7)$ \\
\hline \multirow[t]{2}{*}{ Results } & \multicolumn{2}{|c|}{$n(\%)$} & p-value \\
\hline & Intervention & Control & \\
\hline \multicolumn{4}{|l|}{ Depression (HADS) } \\
\hline 6 weeks & $4(6)$ & $11(15)$ & 0.15 \\
\hline 3 months & $3(6)$ & $5(8)$ & 0.73 \\
\hline 6 months & $2(4)$ & $3(5)$ & 1.0 \\
\hline \multicolumn{4}{|c|}{ Same or better mobility } \\
\hline 6 weeks & $.22(31)$ & $.14(22)$ & 0.32 \\
\hline 3 months & $.32(51)$ & $.24(47)$ & 0.80 \\
\hline 6 months & & orted & \\
\hline Other outcomes & \multicolumn{3}{|c|}{$\begin{array}{l}\text { All other outcomes (pain, physical iliness, functional measures, length of } \\
\text { stay) non-significant, but effect estimates for these outcomes are not } \\
\text { reported. }\end{array}$} \\
\hline Author conclusions & \multicolumn{3}{|c|}{$\begin{array}{l}\text { The intervention did not prevent depression or any other aspect of } \\
\text { disability. }\end{array}$} \\
\hline
\end{tabular}


Figure 5. Brief psychological therapy.

\begin{tabular}{|c|c|c|c|}
\hline \multicolumn{4}{|l|}{ Pirente 2007} \\
\hline Participants & \multicolumn{3}{|c|}{$\begin{array}{l}171 \text { patients severely injured trauma patients admitted to a trauma } \\
\text { centre. }\end{array}$} \\
\hline Intervention & \multicolumn{3}{|c|}{ Up to 8 sessions of individual CBT. } \\
\hline Control & \multicolumn{3}{|l|}{ Treatment as usual. } \\
\hline Summary of results & \multicolumn{3}{|c|}{$\begin{array}{l}\text { While there were no significant between group differences in any of the } \\
\text { outcomes, there was a significant reduction in depression and anxiety } \\
\text { symptoms in the intervention group over the } 12 \text { months of follow up. In } \\
\text { the control group, the only significant reductions in symptoms occurred } \\
\text { between baseline and discharge. }\end{array}$} \\
\hline Follow-up & \multicolumn{3}{|c|}{$\begin{array}{l}\text { Aralysis conducted on } 92 \text { patients with complete follow up at } 6 \text { and } 12 \\
\text { months rather than on } 171 \text { patients who were randomised ( } 45 \\
\text { intervention, } 47 \text { treatment as usual, } 53.8 \% \text { follow-up). }\end{array}$} \\
\hline Results & \multicolumn{2}{|c|}{ Sum score (SD) } & $n$-yalue \\
\hline HRQOL & Intervention & Control & \\
\hline Baseline & $0.48(0.21)$ & $0.54(0.20)$ & 0.17 \\
\hline Discharge & $0.50(0.25)$ & $0.52(0.18)$ & 0.59 \\
\hline 6 months & $0.46(0.18)$ & $0.52(0.23)$ & 0.12 \\
\hline \multirow[t]{2}{*}{12 months } & $+0.47(0.20)$ & $+0.54(0.22)$ & +0.08 \\
\hline \multirow{2}{*}{\multicolumn{4}{|c|}{ Depression (BDI) }} \\
\hline & & & \\
\hline Baseline & $.33(73,3)$ & $21(44.7)$ & 0.006 \\
\hline Discharge & $15(33.3)$ & $10(21.3)$ & 0.24 \\
\hline 6 months & $.19(42.2)$ & $13(27.7)$ & 0.19 \\
\hline 12 months & $\cdot 23(51.1)$ & $14(29.8)$ & 0.09 \\
\hline \multicolumn{4}{|l|}{ Anxiety (STAl) } \\
\hline Baseline & $.26(57.8)$ & $-19(40.4)$ & 0.014 \\
\hline Discharge & $.12(26.7)$ & $.9(19.2)$ & 0.46 \\
\hline 6 months & $.12(33,3)$ & $-10(21.3)$ & 0.24 \\
\hline 12 months & $.20(44.4)$ & $\cdot 12(25.5)$ & 0.08 \\
\hline Author conclusions & \multicolumn{3}{|c|}{$\begin{array}{l}\text { Early CBT does not have a significant effect on the HRQoL of severely } \\
\text { injured patients but shows promising effects on reducing symptoms of } \\
\text { depression and anxiety up to } 12 \text { months after trauma. }\end{array}$} \\
\hline
\end{tabular}


Figure 6. Brief psychological therapy.

\begin{tabular}{|c|c|c|c|}
\hline \multicolumn{4}{|l|}{ Holmes 2007} \\
\hline Participants & \multicolumn{3}{|c|}{$\begin{array}{l}90 \text { adult patients who had suffered a major physical trauma and were } \\
\text { admitted to } 2 \text { trauma centres in Melbourne, Australia. }\end{array}$} \\
\hline Intervention & \multicolumn{3}{|c|}{$\begin{array}{l}\text { Interpersonal Counselling (IPC), from clinical psychologists with specific } \\
\text { training in IPC. Mean number of sessions } 5.9(S D=1.1) \text {. }\end{array}$} \\
\hline Control & \multicolumn{3}{|c|}{$\begin{array}{l}\text { Treatment as usual comprised seeking help for psychological distress } \\
\text { through primary care. }\end{array}$} \\
\hline Summary of results & \multicolumn{3}{|c|}{$\begin{array}{l}\text { No significant differences in any of the mental health outcomes between } \\
\text { the two groups at } 6 \text { months. Subjects with a past history of depression } \\
\text { who received IPC had significantly higher levels of depressive symptoms } \\
\text { at } 6 \text { months. }\end{array}$} \\
\hline \multicolumn{4}{|l|}{ Follow-up } \\
\hline & Intervention & Control & Total ( $\%$ analysed) \\
\hline Baseline & 51 & 39 & 90 \\
\hline 6 months & 27 & 30 & $57(63,3)$ \\
\hline \multirow[t]{2}{*}{ Results } & \multicolumn{2}{|c|}{$n(\%)$} & p-value \\
\hline & Intervention & Control & \\
\hline \multicolumn{4}{|l|}{ Depression (DSM) } \\
\hline Baseline & 0 & $2(6.5)$ & n.s: \\
\hline 6 months & $4(14.8)$ & $6(193)$ & n.s. \\
\hline \multicolumn{4}{|l|}{ PTSD (DSM) } \\
\hline Baseline & 0 & 0 & n.s. \\
\hline 6 months & $4(14.8)$ & $3(9.7)$ & n.s, \\
\hline \multicolumn{4}{|c|}{ Alcohol abuse /dependence (DSM) } \\
\hline Baseline & $1(3.7)$ & $1(32)$ & ns. \\
\hline 6 months & 0 & 0 & n.s. \\
\hline \multicolumn{4}{|c|}{ Substance abuse/ dependence (DSM) } \\
\hline Baseline & $1(3.7)$ & $2(6.5)$ & n.s. \\
\hline 6 months & 0 & $1(3.2)$ & n.s. \\
\hline \multicolumn{4}{|c|}{ Any psychiatric disorder } \\
\hline Baseline & $2(7.4)$ & $4(12.9)$ & n.s. \\
\hline 6 months & $6(22.2)$ & $9(299)$ & n.s. \\
\hline $\begin{array}{l}\text { Physical functioning } \\
\text { (SF-36) }\end{array}$ & \multicolumn{3}{|c|}{ Not significant. Effect estimates and p-values not reported. } \\
\hline Author conclusions & \multicolumn{3}{|c|}{$\begin{array}{l}\text { IPC was not effective as a universal intervention to reduce psychiatric } \\
\text { morbidity after major physical trauma and may increased morbidity in } \\
\text { vulnerable individuals. }\end{array}$} \\
\hline
\end{tabular}


Figure 7. Self-help information.

\begin{tabular}{|c|c|c|c|}
\hline \multicolumn{4}{|l|}{ Turpin 2005} \\
\hline Participants & \multicolumn{3}{|c|}{$\begin{array}{l}291 \text { Accident and Emergency patients who had sustained a physical } \\
\text { injury. }\end{array}$} \\
\hline Intervention & \multicolumn{3}{|c|}{$\begin{array}{l}\text { Self-help information booklet sent within } 6-8 \text { weeks of hospital } \\
\text { attendance. }\end{array}$} \\
\hline Control & \multicolumn{3}{|c|}{ Sent a letter without the information booklet. } \\
\hline Summary of results & \multicolumn{3}{|c|}{$\begin{array}{l}\text { No significant differences in PTSD, depression or anxiety caseness } \\
\text { between groups at either } 3 \text { or } 6 \text { months follow-up. A greater reduction in } \\
\text { PTSD caseness from baseline was observed in the control compared to } \\
\text { the intervention group }(p=0.06 \text { ). }\end{array}$} \\
\hline \multicolumn{4}{|l|}{ Follow-up } \\
\hline & Intervention & Control & Total (\% analysed) \\
\hline Baseline & 145 & 146 & 291 \\
\hline 3 months & 75 & 67 & $142(49.8)$ \\
\hline 6 months & 46 & 54 & $100(34.3)$ \\
\hline \multirow[t]{2}{*}{ Results } & \multicolumn{2}{|c|}{$n(\%)$} & p-value \\
\hline & Intervention & Control & \\
\hline \multicolumn{4}{|l|}{ PTSD (PDS) } \\
\hline 3 months & $19(\cdot 25.3)$ & $10(\cdot 14.9)$ & n.s. \\
\hline 6 months & $14(\cdot 30.4)$ & $10(-18.5)$ & $\mathrm{n} . \mathrm{s}$. \\
\hline \multicolumn{4}{|c|}{ Reduction in PTSD caseness from baseline } \\
\hline 3 months. & $5 / 24(\cdot 20.8)$ & $10 / 20(\cdot 50)$ & 0.06 \\
\hline 6 months & \multicolumn{3}{|c|}{ Not reported } \\
\hline \multicolumn{4}{|l|}{ Depressions (HADS) } \\
\hline 3 months & $15(\cdot 20.0)$ & $10(\cdot 14.9)$ & n.s. \\
\hline 6 months & $18(\cdot 39.1)$ & $7(-12.9)$ & n.s. \\
\hline \multicolumn{4}{|l|}{ Anxiety (HADS) } \\
\hline 3 months & $29(\cdot 38.7)$ & $18(-26.9)$ & n.s. \\
\hline 6 months & $14(\cdot 30.4)$ & $13(-24.1)$ & n.s. \\
\hline Author conclusions & \multicolumn{3}{|c|}{$\begin{array}{l}\text { This trial failed to support the efficacy of providing self-help information } \\
\text { as a preventative strategy to ameliorate PTSD. There is some evidence } \\
\text { that the booklet could delay recovery from PTSD. }\end{array}$} \\
\hline
\end{tabular}


Figure 8. Collaborative care/complex interventions.

Table 3: Collaborative care/complex interventions

\begin{tabular}{|c|c|c|}
\hline \multicolumn{3}{|l|}{ Zatzick 2001} \\
\hline Participants & \multicolumn{2}{|c|}{34 injured patients admitted to a trauma centre in Califormia USA. } \\
\hline Intervention & \multicolumn{2}{|c|}{$\begin{array}{l}4 \text { month collaborative care intervention comprising a personally } \\
\text { assigned trauma support specialist and a brief psychoeducational } \\
\text { intervention targeting PTSD. }\end{array}$} \\
\hline Control & \multicolumn{2}{|l|}{ Treatment as usual. } \\
\hline Summary of results & \multicolumn{2}{|c|}{$\begin{array}{l}\text { At one month post-injury the intervention group demonstrated significant } \\
\text { decreases in PTSD and depressive symptoms but no differences in } \\
\text { episodic alcohol intoxication or functional limitations. At } 4 \text { months post } \\
\text { injury symptoms of depression and PTSD had significantly increased in } \\
\text { the intervention group relative to the controls. }\end{array}$} \\
\hline \multicolumn{3}{|l|}{ Follow-up } \\
\hline & Intervention & Total ( $\%$ analysed) \\
\hline Baseline & 18 & 34 \\
\hline 1 month & \multicolumn{2}{|l|}{ Not reported } \\
\hline 4 months & 14 & $26(74.5)$ \\
\hline Results & Effect size & p-value \\
\hline \multicolumn{3}{|c|}{ Change in PTSD symptoms $\infty$} \\
\hline 1 month & 0.99 & $<0.05$ \\
\hline 4 months & 1,75 & $<0.05$ \\
\hline \multicolumn{3}{|c|}{ Change in depressive symptoms $\infty$} \\
\hline 1 month & 0.58 & 0.07 \\
\hline 4 months & 1.15 & $<0,05$ \\
\hline Other outcomes & \multicolumn{2}{|c|}{$\begin{array}{l}\text { All other outcomes at } 1 \text { and } 4 \text { months (drinking to the point of } \\
\text { intoxication and functional limitations) non-significant, but effect } \\
\text { estimates for these outcomes are not reported. }\end{array}$} \\
\hline Author conclusions & \multicolumn{2}{|c|}{$\begin{array}{l}\text { The results suggest that hospital based care delivered by highly trained } \\
\text { professionals may not be of long enough duration or great enough } \\
\text { intensity, to effect lasting therapeutic change in this population. }\end{array}$} \\
\hline
\end{tabular}




\section{Brief psychological therapies}

Two studies examined the preventive effect of individual CBT (Burns 2007; Pirente 2007) on disability outcomes. No significant between group differences were found for any disability outcome.

\section{Individual CBT}

Burns 2007

This study examined 170 patients over 60 years old who had undergone surgery for hip fracture and who had been classified as not at risk of suffering from depression (score of six or less on the Geriatric Depression Scale). The intervention consisted of up to seven sessions of CBT delivered by an assistant psychologist. The control group received treatment as usual. Outcomes were assessed at six weeks (79.4\% follow up), three months $(66.5 \%$ follow up) and six months (64.7\% follow up). There were no significant differences in any of the outcomes (depression, mobility, pain, physical illness, functioning, or length of hospital stay) at any of the follow-up points. It is possible that the selection of participants who screened negative for depression may have reduced the effectiveness of the intervention on the subsequent development of mental health problems. Indeed, $18 \%$ of the intervention group (and $11 \%$ of the control group) were already taking antidepressants at baseline, suggesting that the screening tool used was not sensitive, creating commonality between groups and possibly further reducing the effect of the intervention.

Pirente 2007

In a similarly sized trial, the authors randomised 171 severely injured trauma patients to receive up to eight sessions of individual CBT or treatment as usual. Only the 92 patients with complete outcome data at both six and 12 months were analysed (53.8\%). There were significant between group differences at baseline with a higher proportion of anxiety $(57.8 \%$ versus $40.4 \%, \mathrm{P}=0.006)$ and depression $(73.3 \%$ versus $44.7 \%, \mathrm{P}=0.014)$ in the intervention compared to the control group. There were no significant differences at any follow-up time between the two groups in any of the outcomes (health-related quality of life (HRQoL), depression or anxiety), possibly because of the initial differences between groups. There was significant within group reduction in depression among the intervention group from surgical ward to discharge $(\mathrm{P}=<0.001)$, from surgical ward to six months follow up $(\mathrm{P}=0.004)$ and from six to 12 months follow up $(\mathrm{P}=0.013)$. The same reduction in anxiety was apparent in the intervention group from surgical ward to discharge $(\mathrm{P}=0.001)$ and from surgical ward to six months follow up $(\mathrm{P}=0.002)$.

\section{Interpersonal therapy}

One study examined the effect of interpersonal therapy (Holmes 2007). No significant differences between groups were found for any outcome.

Holmes 2007

Ninety major physical trauma patients admitted to two trauma centres were randomised to an average of 5.9 Interpersonal Counselling (IPC) sessions delivered by a clinical psychologist. Follow up at six months was $63.3 \%$. There was a high rate of drop-out from the intervention group $(24 / 51,47.1 \%)$, though they did not differ in characteristics from completers. No significant between group differences were found for any of the outcomes (depression, anxiety, PTSD, alcohol and substance abuse, any psychiatric disorder and physical functioning - effect estimates and $\mathrm{P}$ values not reported). The lack of differences between groups may be partly explained by the high degree of 'non-specific psychological support' (mean 22.6 hours) and psychiatric/psychological treatment (mean 0.8 hours) the control group received as well as the small sample size for analysis. Participants with a past history of major depression who received IPC had significantly higher levels of depression at six months $(\mathrm{P}=0.018)$, indicating that the intervention may be harmful to a vulnerable group of individuals.

\section{Self-help information booklet}

One study examined the effect of self-help information delivered as a booklet (Turpin 2005). The intervention had no protective effect on any disability outcome.

Turpin 2005

Two hundred and ninety-one Accident and Emergency patients who had sustained a physical injury were randomised to receive either a self-help information booklet six to eight weeks after hospital attendance, or a letter without the booklet. The booklet described and normalised common physiological, psychological and behavioural reactions to traumatic injury and provided advice on non-avoidance, emotional help and seeking further help. Only $10 \%(291 / 2818)$ of those eligible agreed to participate. There were significant differences between consenters and non-consenters in terms of age, gender and trauma type. Follow up was poor with only $34 \%$ of those randomised followed up at six months. This was partly due to an administrative error which resulted in 66 participants who had completed baseline measures being removed from the analysis. There were no significant differences between groups in anxiety or PTSD symptoms. However, there was evidence that the booklet may have a detrimental impact on mental health status. At three months follow up there was a greater reduction in PTSD cases in the control than the intervention group (P $=0.06$ ), and in an intention-to-treat analysis at six months there was a higher proportion of depressed patients in the intervention rather than the control group ( $18 \%$ versus $7 \%, \mathrm{P}=0.054)$. 


\section{Collaborative care}

One study assessed the effect of collaborative care. The intervention had no protective effect on any disability outcome.

Zatzick 2001

In a pilot study, 34 injured patients admitted to a trauma centre were randomised to receive either collaborative care comprising a personally assigned trauma support specialist and a brief psychoeducational intervention targeting PTSD, or treatment as usual. The trauma support specialists spent on average 1.5 hours with each patient. Follow up at four months was $74.5 \%$. At one-month follow up in intention-to-treat analyses the intervention group had significantly decreased PTSD (effect estimate 0.99, F[1,33] $=6.8 \mathrm{P}<0.05)$ and borderline significant decreased depression (effect estimate $0.58, \mathrm{~F}[1,33]=3.7 \mathrm{P}=0.07$ ) symptoms when compared to the control group. Due to the complex intervention it is not possible to determine which aspect of the intervention had a positive impact on mental health status. At four months the intervention groups symptoms had significantly increased relative to the control groups for both PTSD (effect estimate 1.75, F[1,27] $=6.1 \mathrm{P}<0.05$ ) and depression (effect estimate 1.15, F[1,33] = 6.8 $\mathrm{P}<0.05)$. There were no significant between group differences at either one or four months for the other outcomes: drinking to the point of intoxication and functional limitations.

\section{DISCUSSION}

\section{Summary of main results}

The aim of this review was to evaluate the effectiveness of psychosocial interventions for the prevention of disability following traumatic injury. Five trials were identified. The disparate nature of the trials covering different patient populations, interventions and outcomes meant that it was not possible to pool data meaningfully across studies. Three studies assessed the effect of brief psychological therapies, one assessed the impact of a self-help booklet, and one the effect of collaborative care.

Overall there was no evidence of a protective effect of brief psychological therapies or self-help booklets on preventing disability, and evidence from one trial of a reduction in both PTSD and depressive symptoms one month after injury in those who received a collaborative care intervention combined with a brief psychoeducational intervention (Zatzick 2001). Mental health status was the only disability outcome affected by any intervention. In three trials the psychosocial intervention had a detrimental effect on the mental health status of patients.

\section{Overall completeness and applicability of evidence}

The findings from this review must be viewed in light of the small sample size and the heterogeneous characteristics of trials published in this area.

The absence of effect in the brief psychological therapy trials is surprising given the strong evidence for the effectiveness of these interventions, in particular CBT, in treating a range of mental health problems (Bisson 2007; Hunot 2007; Soo 2007) and other conditions including sleep problems (Montgomery 2003). This may be the result of low power in all three brief psychological therapy trials (the sample size for the analysis ranged from 57 to 135) and relatively large losses to follow up (range $53.8 \%$ to $64.7 \%$ ). The lack of effect may also be due to the universal application of the intervention to all traumatically injured patients including those who may not be at risk of a secondary disability. In particular, one trial specifically excluded those who were considered at risk of developing mental health problems (Burns 2007), and another trial excluded those who had previously suffered a major psychiatric illness or alcohol abuse (Pirente 2007). In addition, the lack of effect of any of the brief psychological therapies on nonmental health outcomes may be due to the targeted approach of these therapies focusing relatively more strongly on mental health status and coping skills per se rather than on physical health and social functioning.

The 'light touch' nature of some of the interventions may explain their lack of effect, in particular the self-help booklet intervention which reported no significant between group differences despite adequate power. It is likely that a short booklet received some weeks after injury is not sufficient to significantly modify feelings and behaviour in order to have a measurable impact on disability outcomes. The only significant effect on a primary outcome in this review was for a complex intervention comprising collaborative care with a dedicated trauma specialist combined with a brief psycho-educational intervention (Zatzick 2001). However the protective effect was not maintained over the medium term once the frequency of contact decreased, possibly suggesting that only complex, time-consuming and therefore costly interventions may have a measurable effect on disability prevention.

There was evidence from three trials that psychosocial interventions have a detrimental effect on the mental health status of some patients (Holmes 2007; Turpin 2005; Zatzick 2001). In one study, subjects with a past history of depression who received interpersonal therapy had significantly higher levels of depressive symptoms at six months (Holmes 2007), while a greater reduction in PTSD 'caseness' between baseline and follow up was observed in the control group compared to those who received an educational booklet (Turpin 2005). In addition, while there was a reduction in depressive and PTSD symptoms in those who had received collaborative care compared to the control group one month after injury, these effects were short-lived. Once patient contact had dropped off by four months post-injury, symptoms of depression and PTSD significantly increased in the intervention group relative to the controls (Zatzick 2001). These findings may be partly 
explained by high rates of drop-out from the intervention group in one of the brief psychological therapy trials (Holmes 2007), perhaps indicating high participant burden resulting in increased participant stress. These results may reflect similar processes to those operating when single session debriefing following a traumatic event leads to increased symptoms of PTSD (Rose 2002). These include 'secondary traumatisation' of the injury and 'medicalising' normal distress whereby increasing awareness of potential psychological distress may paradoxically induce distress in those who would otherwise not have developed it (Rose 2002).

Two studies showed a trend towards a reduction in mental health symptoms over time in both the control and intervention groups, indicating natural recovery from the psychological consequences of physical trauma (Burns 2007; Pirente 2007), and re-enforcing the conclusion that a universally targeted intervention may impose an unnecessary burden on those who may recover naturally from any psychological trauma.

Taken together, our findings cannot be taken as supporting the provision of psychosocial intervention to prevent aspects of disability arising from physical injury. Our findings may indicate that the monitoring of high-risk patients followed by early intervention, whereby resources are allocated at gradually increasing levels to patients whose difficulties do not abate, may be a better strategy for reducing secondary disability arising from traumatic physical injury.

\section{Quality of the evidence}

The quality of trials was generally poor. In particular the quality of reporting of the trials was generally very poor with non-significant effect estimates and the results of many outcomes not reported. With the exception of two trials the sample sizes available for analysis were small, with a large proportion of participants lost to follow up.

\section{Potential biases in the review process}

The wide range of papers selected from our search criteria and the diverse range of studies eligible for inclusion meant that we had to refine our inclusion criteria from the protocol, for example by removing the restriction that the physical injury must have happened within 12 months of the intervention, as many trials did not report this and we sought to be inclusive in our selection of trials. Instead, the emphasis for inclusion was whether the intervention was aimed at prevention rather than treatment.

The poor quality of reporting of outcomes in the trials may have biased the review as effect estimates for many of the non-significant outcomes were not available despite repeated attempts to contact the authors.

\section{Agreements and disagreements with other studies or reviews}

This review contributes to the understanding of psychosocial treatments for the prevention of disability following traumatic injury. This review excluded 62 studies which did not meet our inclusion criteria, indicating a significant body of work in this area. Eleven trials were excluded because they evaluated complex interventions which included but were not restricted to psychosocial interventions. It is possible that the combination of different preventive strategies incorporating medication, psychological interventions and physiotherapy as appropriate may be more effective in preventing the disabling sequelae of traumatic injury than psychosocial interventions alone, though this remains untested in a systematic review.

Seventeen of the excluded studies were trials of the treatment rather than the prevention of disability (primarily mental health problems) following traumatic injury, reflecting the focus of this review on the prevention rather than treatment of secondary conditions. However, given the possible harmful effects that a preventive intervention may have on the mental health status of participants found in this review, in addition to the time and economic cost of such universal interventions, it is important to assess the effect that more targeted interventions may have on ameliorating the negative consequences of traumatic injury. One way of achieving this is to target interventions at groups of patients who have been identified as being at risk of developing a mental or physical disability, or using a stepped care approach to increase the level of intervention based on individual need. A recent systematic review and meta-analysis of early trauma-focused cognitive behavioural therapy to prevent chronic post-traumatic stress disorder and related symptoms concluded that there is evidence for the effectiveness of trauma-focused CBT compared to supportive counselling in preventing chronic PTSD in patients with an initial diagnosis of acute stress disorder. The overall relative risk (RR) for a PTSD diagnosis was 0.56 (95\% CI 0.42 to 0.76 ), 1.09 (95\% CI 0.46 to 2.61 ) and 0.73 (95\% CI 0.51 to 1.04$)$ at three to six months, nine months and three to four years post-treatment, respectively, though this evidence came from one research team and therefore needs replication (Kornør 2008). A wider review into psychosocial interventions after crises and accidents found insufficient research evidence on other types of interventions to conclude about effects (Kornør 2007).

\section{A U THORS, CONCLUSIONS}

\section{Implications for practice}

This review does not provide convincing evidence for the effectiveness of psychosocial interventions for the prevention of disability following traumatic physical injury. No protective effect 
of brief psychological therapies or self-help booklets was found. There was moderate evidence from one trial that collaborative care reduced symptoms of depression and PTSD in the short but not medium term. However, there was also evidence that psychosocial interventions may have a detrimental effect on mental health. Nonetheless, these conclusions are necessarily tentative as they are based on a small number of disparate trials with small to moderate sample sizes. More research, using larger sample sizes and comparable interventions and patient populations to enable pooling of results, is needed before these findings can be confirmed. Any such research should undertake intensive monitoring of participants' short-term response to psychosocial interventions and be vigilant to their potential negative effects.

\section{Implications for research}

The heterogeneity of studies included in this review precluded the pooling of data across studies. In order to combine data across trials we recommend further trials of adequate power which focus on comparable psychosocial interventions, patient populations and outcome measures of disability. Interventions which target mental health as a result of traumatic injury are needed, as this remains the most common disabling sequelae of traumatic injury (Mossey 1990; Schnyder 2001; Shalev 1998; Zatzick 2002) and the outcome which holds the most promise for modification by psychosocial interventions.

The research studies reported on in this review were primarily conducted within North America and Europe. Further research on the prevention of disability following physical injury in different cultures and contexts is needed to develop a fuller understanding of efficacious interventions, particularly in low-income countries where the majority of persons with disabilities live (MacLachlan 2009).

More research is needed into stepped care approaches involving the monitoring of patients at risk of developing a mental health problem followed by early intervention whereby resources are allocated at gradually increasing levels to patients whose symptoms do not abate.

\section{ACKNOWLEDGEMENTS}

This review was supported by a Cochrane Fellowship grant from the Health Research Board (Ireland) to Malcolm MacLachlan.

Mary De Silva is supported by an ESRC/MRC Interdisciplinary Post Doctoral Fellowship.

Vikram Patel is supported by a Wellcome Trust Senior Clinical Research Fellowship in Tropical Medicine.

We thank the Cochrane Injuries Group for assistance throughout the review process, in particular Ian Roberts for comments on the initial review design, Karen Blackhall for conducting the search and Emma Sydenham and Pablo Perel for support throughout the process.

\section{R E F E R E N C E S}

\section{References to studies included in this review}

Burns 2007 \{published data only\}

Burns A, Banerjee S, Morris J, Woodward Y, Baldwin R, Proctor $\mathrm{R}$, et al.Treatment and prevention of depression after surgery for hip fracture in older people: randomized, controlled trials. Journal of the American Geriatrics Society 2007;55(1):75-80.

Holmes 2007 \{published data only\}

Holmes A, Hodgins G, Adey S, Menzel S, Danne P, Kossmann T, et al.Trial of interpersonal counselling after major physical trauma. Australian and New Zealand Journal of Psychiatry 2007;41(11):926-33.

Pirente 2007 \{published data only\}

Pirente N, Blum C, Wortberg S, Bostanci S, Berger E, Lefering R, et al.Quality of life after multiple trauma: the effect of early onset psychotherapy on quality of life in trauma patients. Langenbecks Archives of Surgery 2007;392 (6):739-45.

Turpin 2005 \{published data only\}

Turpin G, Downes M, Mason S. Effectiveness of giving self-help information acute traumatic injury: a randomised controlled trial. British Journal of Psychiatry 2005;187: 76-82.

Zatzick 2001 \{published data only\}

Zatzick DF, Roy-Byrne P, Russo JE, Rivara FP, Koike A, Jurkovich GJ, et al.Collaborative interventions for physically injured trauma survivors: a pilot randomized effectiveness trial. General Hospital Psychiatry 2001;23(3):114-23.

\section{References to studies excluded from this review}

Allen 1996 \{published data only\}

Allen K, Blascovich J. The value of service dogs for people with severe ambulatory disabilities - a randomized controlled trial. JAMA 1996; Vol. 275, issue 13:1001-6.

Andersson 2005 \{published data only\}

Andersson AL, Dahlback LO, Bunketrop O. Psychosocial aspects of road traffic trauma - benefits of an early intervention?. Injury 2005; Vol. 36, issue 8:917-26.

Bisson 2004 \{published data only\}

Bisson JI, Shepherd JP, Joy D, Probert R, Newcombe RG. Early cognitive-behavioural therapy for post-traumatic stress 
symptoms after physical injury. Randomised controlled trial. British Journal of Psychiatry 2004; Vol. 184:63-9.

Bordow 1979 \{published data only\}

Bordow S, Porritt D. An experimental evaluation of crisis intervention. Social Science \& Medicine 1979; Vol. 13A, issue 3:251-6.

Bryant 1998 \{published data only\}

Bryant, RA, Harvey AG, Dang ST, Sackville T, Basten

C. Treatment for acute stress disorder: a comparison of cognitive-behavioural therapy and supportive counseling. Journal of Consulting and Clinical Psychology 1998;66: 862-6.

Bugg (in press) \{published data only\}

Bugg A, Mason S. Preventing post-traumatic stress disorder following a traumatic injury: evaluation of the Pennebaker writing paradigm. Doctor of Clinical Psychology. Sheffield: Sheffield, In press (submitted):Complete.

\section{Castillo 2002 \{published data only\}}

Castillo J, Sanchez-Sosa JJ. Well-being and medical recovery in the critical care unit: the role of the nurse-patient interaction. Salud Mental 2002; Vol. 25, issue 2:21-31.

Christakou 2007 \{published data only\}

Christakou A, Zervas Y, Lavallee D. The adjunctive role of imagery on the functional rehabilitation of a grade II ankle sprain. Human Movement Science 2007; Vol. 26, issue 1: 141-54.

Corey 1996 \{published data only\}

Corey DT, Koepfler LE, Etlin D, Day HI. A limited functional restoration program for injured workers: A randomized trial. Journal of Occupational Rehabilitation 1996; Vol. 6, issue 4:239-49.

\section{Craig 1998 \{published data only\}}

Craig A, Hancock K, Chang E, Dickson H. The effectiveness of group psychological intervention in enhancing perceptions of control following spinal cord injury. Australian \& New Zealand Journal of Psychiatry 1998; Vol. 32, issue 1:112-8.

Cramer 2007 \{published data only\}

Cramer SC, Orr EL, Cohen MJ, Lacourse MG. Effects of motor imagery training after chronic, complete spinal cord injury. Experimental Brain Research 2007; Vol. 177, issue 2:233-42.

\section{Cupal 2001 \{published data only\}}

Cupal DD, Brewer BW. Effects of relaxation and guided imagery on knee strength, reinjury anxiety, and pain following anterior cruciate ligament reconstruction. Rehabilitation Psychology 2001; Vol. 46:28-43.

\section{Drechsel-Schlund 2003 \{published data only\}}

Drechsel-Schlund C, Plinske W. Accidents at the workplace and psychological reactions - empirical research on the prevention of mental disorders after accidents at the workplace. [German]. Aktuelle Traumatologie 2003; Vol. 33, issue 6:295-9.

\section{Dunn 2003 \{published data only\}}

Dunn C. Brief motivational interviewing interventions targeting substance abuse in the acute care medical setting.
Seminars in Clinical Neuropsychiatry 2003; Vol. 8, issue 3: 188-96.

\section{Dunn 2004 \{published data only\}}

Dunn C, Droesch RM, Johnston BD, Rivara FP.

Motivational interviewing with injured adolescents in the emergency department: in-session predictors of change. Behavioural and Cognitive Psychotherapy 2004; Vol. 32: 113-6.

\section{Ehlers 2003 \{published data only\}}

Ehlers A, Clark DM, Hackmann A, McManus F, Fennell M, Herbert C, et al.A randomized controlled trial of cognitive therapy, a self-help booklet, and repeated assessments as early interventions for posttraumatic stress disorder. Archives of General Psychiatry 2003; Vol. 60:1024-32.

\section{Evans 1998 \{published data only\}}

Evans RL, Connis RT, Haselkorn JK. Hospital-based rehabilitative care versus outpatient services: effects on functioning and health status. Disability and Rehabilitation 1998; Vol. 20, issue 8:298-307.

Evans 2001 \{published data only\}

Evans RL, Hendricks RD. Comparison of subacute rehabilitative care with outpatient primary medical care. Disability \& Rehabilitation 2001; Vol. 23, issue 12:531-8.

Fauerbach 2002 \{published data only\}

Fauerbach JA, Lawrence JW, Haythornthwaite JA, Richter L. Coping with the stress of a painful medical procedure. Behaviour Research and Therapy 2002; Vol. 40, issue 9: 1003-15.

Fecteau 1999 \{published data only\}

Fecteau G, Nicki R. Cognitive behavioural treatment of post traumatic stress disorder after motor vehicle accident. Behavioural \& Cognitive Psychotherapy 1999; Vol. 27, issue 3:201-14.

\section{Foa 1995 \{published data only\}}

Foa, EB, Hearst-Ikeda D, Perry KJ. Evaluation of a brief cognitive behavioural program for the prevention of chronic PTSD in recent assault victims. Journal of Consulting and Clinical Psychology 1995;63:948-55.

Fronek 2005 \{published data only\}

Fronek P, Booth S, Kendall M, Miller D, Geraghty T. The effectiveness of a sexuality training program for the interdisciplinary spinal cord injury rehabilitation team. Sexuality and Disability 2005; Vol. 23, issue 2:51-63.

Girolami 2005 \{published data only\}

Girolami P. The impact of a school reentry program on the psychosocial adjustment of children with burn injuries. Dissertation Abstracts International: Section B: The Sciences and Engineering 2005.

\section{Hagglund 2007 \{published data only\}}

Hagglund M, Walden M, Ekstrand J. Lower reinjury rate with a coach-controlled rehabilitation program in amateur male soccer: a randomized controlled trial. American Journal of Sports Medicine 2007; Vol. 35, issue 9:1433-42.

Hagsten 2006 \{published data only\}

Hagsten B, Svensson O, Gardulf A. Health-related quality of life and self-reported ability concerning ADL and IADL 
after hip fracture: a randomized trial. Acta Orthopaedica 2006; Vol. 77, issue 1:114-9.

\section{Hazard 2000 \{published data only\}}

Hazard RG, Reid S, Haugh LD, McFarlane G. A controlled trial of an educational pamphlet to prevent disability after occupational low back injury. Spine 2000;25(11):1419-23.

Jensen 2001 \{published data only\}

Jensen IB, Bergstrom G, Ljungquist T, Bodin L, Nygren AL. A randomized controlled component analysis of a behavioral medicine rehabilitation program for chronic spinal pain: are the effects dependent on gender?. Pain 2001; Vol. 91:65-78

\section{Kennedy 2003 \{published data only\}}

Kennedy P, Duff J, Evans M, Beedie A. Coping effectiveness training reduces depression and anxiety following traumatic spinal cord injuries. British Journal of Clinical Psychology 2003;42(1):41-52.

\section{King 1999 \{published data only\}}

King C, Kennedy P. Coping effectiveness training for people with spinal cord injury: preliminary results of a controlled trial. British Journal of Clinical Psychology 1999; Vol. 38, issue Pt 1:5-14.

\section{Kwon 2006 \{published data only\}}

Kwon IS, Kim J, Park KM. Effects of music therapy on pain, discomfort, and depression for patients with leg fractures. Taehan Kanho Hakhoe chi 2006; Vol. 36, issue 4:630-6.

\section{Latimer 2006 \{published data only\}} Latimer A, Martin, Ginis K, Arbour K. The efficacy of an implementation intention intervention for promoting physical activity among individuals with spinal cord injury: a randomized controlled trial. Rehabilitation Psychology 2006;51(4):273-80.

Lindstrom 1992 \{published data only\} Lindstrom I, Ohlund C, Eek C, Wallin L, Peterson LE, Fordyce WE, et al.The effect of graded activity on patients with subacute low-back-pain - a randomized prospective clinical-study with an operant-conditioning behavioralapproach. Physical Therapy 1992; Vol. 72, issue 4:279-90.

McFarlane 2006 \{published data only\}

McFarlane JM, Groff JY, O’Brien JA, Watson K. Secondary prevention of intimate partner violence - a randomized controlled trial. Nursing Research 2006; Vol. 55, issue 1: 52-61.

\section{Melnyk 2004 \{published data only\}}

Melnyk BM, Alpert-Gillis L, Feinstein NF, Crean HF, Johnson J, Fairbanks E, et al.Creating opportunities for parent empowerment: program effects on the mental health/coping outcomes of critically ill young children and their mothers. Pediatrics 2004; Vol. 113, issue 6:E597-607.

Menzel 2006 \{published data only\}

Menzel NN, Robinson ME. Back pain in direct patient care providers: early intervention with cognitive behavioral therapy. Pain Management Nursing 2006;7(2):53-63.
Miller 1975 \{published data only\}

Miller DK, Wolfe M, Spiegel MH. Therapeutic groups for patients with spinal cord injuries. Archives of Physical Medicine \& Rehabilitation 1975; Vol. 56, issue 3:130-5.

Mitchell 1994 \{published data only\}

Mitchell R, I, Carmen G. The functional restoration approach to the treatment of chronic pain in patients with soft tissue and back injuries. Spine 1994; Vol. 19:633-42.

\section{Moore 1983 \{published data only\}}

Moore LE, Kaplan JZ. Hypnotically accelerated burn wound healing. American Journal of Clinical Hypnosis 1983; Vol. 26:16.

Norman 2004 \{published data only\}

Norman SA, Lumley MA, Dooley JA, Diamond MP. For whom does it work? Moderators of the effects of written emotional disclosure in a randomized trial among women with chronic pelvic pain. Psychosomatic Medicine 2004; Vol. 66, issue 2:174-83.

Oliveira 2006 \{published data only\}

Oliveira A, Gevirtz R, Hubbard D. A psycho-educational video used in the emergency department provides effective treatment for whiplash injuries. Spine 2006; Vol. 31, issue 15:1652-7.

Ottosson 2007 \{published data only\}

Ottosson C, Pettersson H, Johansson SE, Nyren O, Ponzer

$S$. Recovery after minor traffic injuries: a randomized controlled trial. Plos Clinical Trials 2007; Vol. 2, issue 3.

\section{Pain 2007 \{published data only\}}

Pain H, Soopramanien A, Dallolio L, Prior R, Menarini M, Ventura $\mathrm{M}$, et al.Outcomes from a randomized controlled trial of tele-rehabilitation for people with spinal cord injuries. Journal of Telemedicine and Telecare 2007;13(Suppl 1):46-8.

Phillips 2001 \{published data only\} Phillips VL, Vesmarovich S, Hauber R, Wiggers E, Egner A. Telehealth: reaching out to newly injured spinal cord patients. Public Health Reports 2001; Vol. 116, issue Suppl 1:94-102.

Porritt 1979 \{published data only\} Porritt D. Social support in crisis: quantity or quality?. Social Science \& Medicine 1979; Vol. 13A, issue 6:715-21.

Ross 1996 \{published data only\} Ross MJ, Berger RS. Effects of stress inoculation training on athletes' postsurgical pain and rehabilitation after orthopedic injury. Journal of Consulting and Clinical Psychology 1996; Vol. 64, issue 2:406-10.

Rotem-Lehrer 2007 \{published data only\} Rotem-Lehrer N, Laufer Y. Effect of focus of attention on transfer of a postural control task following an ankle sprain. Journal of Orthopaedic and Sports Physical Therapy 2007; Vol. 37, issue 9:564-9.

Rottkamp 1976 \{published data only\}

Rottkamp BC. An experimental nursing study: a behavior modification approach to nursing therapeutics in body positioning of spinal cord-injured patients. Nursing Research 1976; Vol. 25, issue 3:181-6. 
Rowland 2006 \{published data only\}

Rowland JL, White GW, Wyatt DA. Analysis of an intervention to reduce or prevent secondary conditions for people with spinal cord injuries. Journal of Clinical Psychology in Medical Settings 2006; Vol. 13, issue 3: 263-71.

Scholes 2007 \{published data only\}

Scholes C, Turpin G, Mason S. A randomised controlled trial to assess the effectiveness of providing self-help information to people with symptoms fo acute stress disorder following a traumatic injury. Behaviour Research and Therapy 2007; Vol. 45:2527-36.

Scholten-Peeters 2006 \{published data only\} Scholten-Peeters GG, Neeleman-van der Steen CW, van der Windt DA, Hendriks EJ, Verhagen AP, Oostendorp RA. Education by general practitioners or education and exercises by physiotherapists for patients with whiplashassociated disorders? A randomized clinical trial. Spine 2006; Vol. 31, issue 7:723-31.

Sirles 1991 \{published data only\} Sirles AT, Brown K, Hilyer JC. Effects of back school education and exercise in back injured municipal workers. Official Journal of the American Association of Occupational Health Nurses 1991;39(1):7-12.

Smith 1984 \{published data only\}

Smith JE, Rachman SJ. Non-accidental injury to children - II. A controlled evaluation of a behavioural management programme. Behaviour Research and Therapy 1984; Vol. 22 , issue 4:349-66.

Soderstrom 2007 \{published data only\}

Soderstrom CA, DiClemente CC, Dischinger PC, Hebel JR, McDuff DR, Auman KM, et al.A controlled trial of brief intervention versus brief advice for at-risk drinking trauma center patients: commentary. Journal of Trauma Injury, Infection and Critical Care 2007;62(5):1111-2.

Söderlund 2007 \{published data only\}

Söderlund A, Lindberg P. Cognitive behavioural components in physiotherapy management of chronic whiplash associated disorders (WAD) - a randomised group study. Giornale Italiano di Medicina del Lavoro ed Ergonomia 2007; Vol. 29, issue 1 Suppl A:A5-11.

Ventegodt 2004 \{published data only\}

Ventegodt S, Merrick J, Andersen NJ, Bendix T. A combination of gestalt therapy, Rosen Body Work, and Cranio Sacral therapy did not help in chronic whiplashassociated disorders (WAD) - results of a randomized clinical trial. The Scientific World Journal 2004; Vol. 4:1055-68

Vick 2001 \{published data only\}

Vick T. Post traumatic stress disorder and the intensive care patient. 2001; Vol. Wales:Complete.

Vick 2004 \{published data only\}

Vick T. Psychological follow-up after critical illness: a randomised controlled trial of cognitive behavioural therapy for traumatic stress symptoms following critical care admission. 2004; Vol. Wales:Complete.
Wagner 2007 \{published data only\}

Wagner AW, Zatzicka DF, Ghesquierea A, Jurkovicha GJ. Behavioral activation as an early intervention for posttraumatic stress disorder and depression among physically injured trauma survivors. Cognitive and Behavioral Practice 2007; Vol. 14, issue 4:341-9.

Wise 2002 \{published data only\}

Wise JB, Ellis GD, Trunnell EP. Effects of a curriculum designed to generalize self-efficacy from weight-training exercises to activities of daily living among adults with spinal injuries. Journal of Applied Social Psychology 2002; Vol. 32 , issue 3:500-21.

Yates 2000 \{published data only\}

Yates K. Social support and well-being in minor burns victims. 2000; Vol. Northern/Yorkshire Regional Office: Complete.

Zatzick 2004 \{published data only\}

Zatzick D, Roy-Byrne P, Russo J, Rivara F, Droesch R, Wagner A, et al.A randomized effectiveness trial of stepped collaborative care for acutely injured trauma survivors. Archives of General Psychiatry 2004; Vol. 61, issue 5: 498-506.

Zemper 2003 \{published data only\} Zemper ED, Tate DG, Roller S, Forchheimer M, Chiodo A, Nelson VS, et al.Assessment of a holistic wellness program for persons with spinal cord injury. American Journal of Physical Medicine \& Rehabilitation 2003; Vol. 82, issue 12:957-68.

\section{References to studies awaiting assessment}

\section{Humphreys 2003 \{published data only\}}

Humphreys AL. Minimising the psychological effects of road traffic accidents. 2003; Vol. North West Regional Office:Complete. [: N0280119831]

\section{McKinlay 2003 \{published data only\}}

McKinlay R. A comparison of eye movement desensitisation and reprocessing treatment and relaxation therapy in patients with chronic pain. 2003; Vol. Scotland. [: N0609137009]

Tecic unpublished \{published and unpublished data\} Tecic T, Althaus A, Schneider A, Lefering R, Bouillon B, Rehm KE, et al.A randomized controlled trial comparing early short-term inpatient psychotherapeutic treatment with additional ongoing ambulatory psychotherapy in trauma patients. Unpublished.

\section{Additional references}

Bisson 2007

Bisson J, Andrew M. Psychological treatment of posttraumatic stress disorder (PTSD). Cochrane Database of Systematic Reviews 2007, Issue 3. [DOI: 10.1002/ 14651858.CD003388]

\section{Gersons 2005}

Gersons B, Olff M. Coping with the aftermath of trauma. BMJ (Clinical Research Ed.) 2005;330:1038-9. 


\section{Hunot 2007}

Hunot V, Churchill R, Teixeira V, Silva de Lima M. Psychological therapies for generalised anxiety disorder. Cochrane Database of Systematic Reviews 2007, Issue 1. [DOI: 10.1002/14651858.CD001848]

\section{Kornør 2007}

Kornør H, Winje D, Ekeberg Ø, Johansen K, Weisæth L, Ormstad SS, et al.Psychosocial interventions after crises and accidents. Oslo 2007

\section{Kornør 2008}

Kornør H, Winje D, Ekeberg O, Weisaeth L, Kirkehei I, Johansen $\mathrm{K}$, et al.Early trauma-focused cognitivebehavioural therapy to prevent chronic post-traumatic stress disorder and related symptoms: a systematic review and meta-analysis. BMC Psychiatry 2008;8:81.

\section{MacLachlan 2009}

MacLachlan M, Swartz L. Disability and international development: towards inclusive global health. New York: Springer-Verlag, 2009.

\section{Moher 1999}

Moher D, Cook D, Eastwood S, Olkin, I, Rennie D, Stroup D. Improving the quality of reports of meta-analyses of randomised controlled trials: the QUOROM statement. Lancet 1999;354:1896-1900.

\section{Montgomery 2003}

Montgomery P, Dennis J. Cognitive behavioural interventions for sleep problems in adults aged 60+ Cochrane Database of Systematic Reviews 2003, Issue 1. [DOI: 10.1002/14651858.CD003161]

\section{Mossey 1990}

Mossey J, Knott K, Craik R. The effects of persistent depressive symptoms on hip fracture recovery. Journal of Gerontology 1990;45:163-8.

\section{Review Manager}

The Nordic Cochrane Centre. The Cochrane Collaboration. Review Manager. 5.0. Copenhagen: The Nordic Cochrane Centre. The Cochrane Collaboration, 2008.

\section{Rose 2002}

Rose S, Bisson J, Wessely S. Psychological debriefing for preventing post traumatic stress disorder. Cochrane Database of Systematic Reviews 2002, Issue 2. [DOI: 10.1002/ 14651858.CD000560]

\section{Ruddy 2005}

Ruddy R, House A. Psychosocial interventions for conversion disorder. Cochrane Database of Systematic Reviews 2005, Issue 4. [DOI: 10.1002/14651858.CD005331]

\section{Schnyder 2001}

Schnyder U, Moergeli H, Trentz O, Klaghofer R, Buddesberg C. Prediction of psychiatric morbidity in severely injured accident victims at one-year follow-up. American Journal of Respiratory and Critical Care Medicine 2001;164:653-6.

\section{Schulz 1995}

Schulz K, Chalmers I, Hayes RJ, Altman DG. Empirical evidence of bias. Dimensions of methodological quality associated with estimates of treatment effects in controlled trials. JAMA 1995;273(5):408-12.

\section{Shalev 1998}

Shalev A, Freedman S, Peri T, Brandes D, Sahar T, Orr S, et al.Prospective study of posttraumatic stress disorder and depression following trauma. American Journal of Psychiatry 1998;155:630-7.

Sobel 1995

Sobel D. Rethinking medicine: improving health outcomes with cost-effective psychosocial interventions. Psychosomatic Medicine 1995;57:234-44.

Soo 2007

Soo C, Tate R. Psychological treatment for anxiety in people with traumatic brain injury. Cochrane Database of Systematic Reviews 2007, Issue 3. [DOI: 10.1002/ 14651858.CD005239.pub2]

\section{WHO 2002}

Peden M, McGee K, Sharma G. The injury chart book: a graphical overview of the global burden of injuries. World Health Organizsation, 2002.

\section{Zatzick 2002}

Zatzick D, Kang S, Muller H, Russo J, Rivara F, Katon $\mathrm{W}$, et al.Predicting posttraumatic distress in hospitalized trauma survivors with acute injuries. American Journal of Psychiatry 2002;159:941-6.

* Indicates the major publication for the study 
CHARACTERISTICS OF STUDIES

\section{Characteristics of included studies [ordered by study ID]}

Burns 2007

\begin{tabular}{|c|c|c|}
\hline Methods & \multicolumn{2}{|c|}{ Randomised controlled trial } \\
\hline Participants & \multicolumn{2}{|c|}{$\begin{array}{l}170 \text { patients over } 60 \text { years old who have undergone surgery for hip fracture in orthopaedic } \\
\text { units in Manchester, UK, in the previous } 2 \text { weeks and who were not depressed (scored } 6 \\
\text { or less on the Geriatric Depression Scale (GDS)). } 85 \text { in the intervention group and } 85 \\
\text { control. Mean age } 81 \text { years and } 50 \% \text { were female }\end{array}$} \\
\hline Interventions & \multicolumn{2}{|c|}{$\begin{array}{l}\text { Up to } 7 \text { sessions of individual CBT delivered by an assistant psychologist, supervised by } \\
\text { a clinical psychologist versus treatment as usual }\end{array}$} \\
\hline Outcomes & \multicolumn{2}{|c|}{$\begin{array}{l}\text { Primary outcome (assessed at } 6 \text { weeks): } \\
\text { - Depression: Hospital Anxiety and Depression Scale (HADS) } \\
\text { Other outcomes assessed at } 6 \text { weeks, } 3 \text { and } 6 \text { months: } \\
\text { - Fear of falling: Modified Falls Efficacy Scale } \\
\text { - Pain: short form McGill pain questionnaire and the Wong-Baker pain rating scale } \\
\text { - Mobility: Timed-Up-and-Go Test and the modified gait test }\end{array}$} \\
\hline Notes & \multicolumn{2}{|c|}{$\begin{array}{l}\text { The trial had a separate arm for patients who scored over } 6 \text { on the GDS. As these patient } \\
\text { had been screened for depression and the CBT was administered to treat rather than } \\
\text { prevent depression, this arm of the trial was excluded from this review }\end{array}$} \\
\hline \multicolumn{3}{|l|}{ Risk of bias } \\
\hline Item & Authors' judgement & Description \\
\hline Adequate sequence generation? & Yes & $\begin{array}{l}\text { Computer generated randomisation stratified by hospi- } \\
\text { tal, block size } 4\end{array}$ \\
\hline Allocation concealment? & Yes & Independent central telephone randomisation scheme. \\
\hline $\begin{array}{l}\text { Incomplete outcome data addressed? } \\
\text { All outcomes }\end{array}$ & Unclear & $\begin{array}{l}6 \text {-week follow up available for } 75 \% \text { of intervention group } \\
\text { and } 84 \% \text { of treatment as usual group. No significant dif- } \\
\text { ferences in baseline characteristics of those lost to follow } \\
\text { up and those included } \\
\text { 3-month follow up: } 66.5 \% \text { and } 6 \text {-month follow up } 64 \text {. } \\
7 \%\end{array}$ \\
\hline Free of selective reporting? & No & $\begin{array}{l}\text { No reporting of questionnaires other than HADS and } \\
\text { new measures not previously introduced. Non-signifi- } \\
\text { cant effect estimates and many 6-month outcomes not } \\
\text { reported }\end{array}$ \\
\hline
\end{tabular}

Psychosocial interventions for the prevention of disability following traumatic physical injury (Review) 
Burns 2007 (Continued)

\begin{tabular}{|l|l|l|l|l|l|l|l}
\hline Free of other bias? & No & $\begin{array}{l}\text { 1. Selection of non-depressed via the GDS may reduce } \\
\text { effectiveness of intervention by restricting the sample to } \\
\text { those at low risk of depression } \\
\text { 2. Use of anti-depressants in intervention and treatment } \\
\text { as usual groups questions validity of psychometrics and/ } \\
\text { or clinical judgement and creates commonality between } \\
\text { groups thereby possibly reducing intervention effect size } \\
\text { 3. Small sample size and lack of power for secondary } \\
\text { outcomes }\end{array}$ \\
\hline Intention to Treat analysis? & Yes & - \\
\hline Blinding of outcome assessment? & Unclear & Insufficient information \\
\hline
\end{tabular}

Holmes 2007

\begin{tabular}{|c|c|}
\hline Methods & Randomised controlled trial. \\
\hline Participants & $\begin{array}{l}\text { All patients admitted to } 2 \text { trauma centres in Melbourne, Australia, over an } 18 \text {-month } \\
\text { period, who were } 18 \text { years or older and had suffered a major physical trauma (defined } \\
\text { as one or more of Injury Severity Score }>15 \text {; serious injury to } 2 \text { or more body systems; } \\
\text { urgent surgery for non-limb injuries; or injuries requiring mechanical ventilation for > } \\
24 \text { hours) were eligible } \\
90 / 146 \text { eligible patients randomised ( } 51 \text { intervention, } 39 \text { control). Mean age } 37 \text { years, } \\
69.3 \% \text { male }\end{array}$ \\
\hline Interventions & $\begin{array}{l}\text { Interpersonal Counselling (IPC), from clinical psychologists with specific training in } \\
\text { IPC. Mean number of sessions 5.9 }(\mathrm{SD}=1.1) \text {. Treatment as usual comprised seeking help } \\
\text { for psychological distress through primary care. On average the control group received an } \\
\text { average of } 22.6 \text { hours of non-specific psychological support (physical and occupational) } \\
\text { and saw a psychologist or psychiatrist for a mean of } 0.8 \text { hours }\end{array}$ \\
\hline Outcomes & $\begin{array}{l}\text { Outcomes assessed at } 3 \text { and } 6 \text { months: } \\
\text { - Psychiatric diagnosis: Structured Clinical Interview for DSM IV (SCID) } \\
\text { - Depression and anxiety: Beck Depression Inventory, Hospital Anxiety and } \\
\text { Depression Scale } \\
\text { - PTSD: Post-Traumatic Checklist } \\
\text { - Alcohol use: Alcohol Use Disorders Identification Test } \\
\text { - Pain: visual analogue pain scale } \\
\text { Outcome assessed at } 6 \text { months: } \\
\text { - Health related function: SF-36 }\end{array}$ \\
\hline Notes & $\begin{array}{l}\text { The authors state that "The mean hours of specific psychological intervention (other } \\
\text { than IPC) and non-specific therapy did not differ between the groups", the meaning of } \\
\text { this is unclear, especially as regards the nature of other types of "specific psychological } \\
\text { intervention" that were used as part of treatment as usual }\end{array}$ \\
\hline
\end{tabular}

Risk of bias

Psychosocial interventions for the prevention of disability following traumatic physical injury (Review) 
Holmes 2007 (Continued)

\begin{tabular}{|c|c|c|}
\hline Item & Authors' judgement & Description \\
\hline Adequate sequence generation? & Yes & $\begin{array}{l}\text { Computer generated. Intervention allocated in a ratio } \\
\text { of } 5: 4 \text { in expectation of greater losses to follow up in } \\
\text { intervention group }\end{array}$ \\
\hline Allocation concealment? & Yes & $\begin{array}{l}\text { Research officer made blinded selection from a box of } \\
\text { sealed envelopes }\end{array}$ \\
\hline $\begin{array}{l}\text { Incomplete outcome data addressed? } \\
\text { All outcomes }\end{array}$ & No & $\begin{array}{l}\text { Differential losses to follow up may have affected results } \\
\text { with only } 53 \% \text { (27/51) of intervention group complet- } \\
\text { ing IPC therapy and available for 6-month follow up } \\
\text { compared to } 80 \%(31 / 39) \text { of the control group. No sig- } \\
\text { nificant differences between those lost to follow up and } \\
\text { those with complete follow up, and those who did and } \\
\text { did not complete the intervention }\end{array}$ \\
\hline Free of selective reporting? & Yes & - \\
\hline Free of other bias? & No & $\begin{array}{l}\text { 1. The intervention group received less 'intervention } \\
\text { time' in terms of psychological support than the control } \\
\text { group (mean }=5.9 \text { hours versus } 22.6 \text { hours) } \\
\text { 2. Participants who commenced but failed to complete } \\
\text { therapy had significantly higher alcohol use than those } \\
\text { who completed } \\
\text { 3. Low power due to small sample size and high rate of } \\
\text { drop- out in intervention group }\end{array}$ \\
\hline Intention to Treat analysis? & No & - \\
\hline Blinding of outcome assessment? & Unclear & $\begin{array}{l}\text { Psychiatric diagnosis (primary outcome) assessor } \\
\text { blinded at } 6 \text { months follow-up. other outcomes not } \\
\text { blinded }\end{array}$ \\
\hline
\end{tabular}

Pirente 2007

\begin{tabular}{|c|c|}
\hline Methods & Randomised controlled trial. \\
\hline Participants & $\begin{array}{l}171 \text { patients admitted to } 2 \text { trauma centres in Cologne, Germany with at least } 2 \text { injuries } \\
\text { with a combined Abbreviated Injury Scale score of }>=6 \text {, aged between } 18 \text { and } 70 \text { years, } \\
\text { well orientated in time/person/location at time of contact. } 171 / 184 \text { eligible patients } \\
\text { randomised }(83=\text { intervention, } 88=\text { control). Complete outcome data available for } 92 \\
\text { patients }(45=\text { intervention, } 47=\text { control). } 70.7 \% \text { male, mean age } 38 \text { years }\end{array}$ \\
\hline
\end{tabular}

Interventions

CBT of up to 8 sessions given by a research psychologist trained in CBT with a maximum of 3 sessions per week. Compared to a treatment as usual group (standard hospital care without formal psychosocial intervention). Control groups told they would not receive CBT intervention 
Pirente 2007 (Continued)

\begin{tabular}{l}
\hline Primary outcome measured at discharge, and at 6 and 12 months: \\
- Health Related Quality of Life (HLQOL) composite sum score comprised of \\
parts of several questionnaires: Short Form Health Survey Questionnaire (SF-36); \\
Symptom Check-list-90; Beck Depression Inventory (BDI); State-Trait Anxiety \\
Inventory (STAI) and the social support questionnaire (F-SOZU) \\
Secondary outcomes measured at discharge and at 6 and 12 months: \\
- Depression and anxiety: BDI, SCL90-R and STAI \\
\hline
\end{tabular}

Notes

Risk of bias

\begin{tabular}{|c|c|c|}
\hline Item & Authors' judgement & Description \\
\hline Adequate sequence generation? & Yes & $\begin{array}{l}\text { Computer generated, stratified for hospital and for mild } \\
\text { or no brain injury }\end{array}$ \\
\hline Allocation concealment? & Yes & Central allocation. \\
\hline $\begin{array}{l}\text { Incomplete outcome data addressed? } \\
\text { All outcomes }\end{array}$ & No & $\begin{array}{l}\text { Substantial losses to follow up with complete outcome } \\
\text { data only available for } 92 / 171 \text { patients randomised. Rea- } \\
\text { sons for losses explained and no significant differences in } \\
\text { demographic characteristics were found between those } \\
\text { lost to follow up and those with complete follow up }\end{array}$ \\
\hline Free of selective reporting? & No & $\begin{array}{l}\text { Effect estimates for social aspects, pain and physical func- } \\
\text { tioning not reported }\end{array}$ \\
\hline Free of other bias? & Unclear & $\begin{array}{l}\text { 1. Levels of depression and anxiety at baseline were sig- } \\
\text { nificantly higher for the intervention compared to the } \\
\text { control group. Both intervention and control groups im- } \\
\text { proved, but between group differences were not signif- } \\
\text { cant. It may be that the intervention is more effective in } \\
\text { treating more severe psychological problems than is the } \\
\text { control } \\
\text { 2. Rationale for selection of composite HRQOL measure } \\
\text { not given. Use of individual scales may be more valid }\end{array}$ \\
\hline Intention to Treat analysis? & No & $\begin{array}{l}\text { Analyses only performed on the } 92 \text { patients with com- } \\
\text { plete data rather than on the } 171 \text { patients who were ran- } \\
\text { domised }\end{array}$ \\
\hline Blinding of outcome assessment? & Yes & $\begin{array}{l}\text { Outcomes were assessed using a self-completion postal } \\
\text { questionnaire }\end{array}$ \\
\hline
\end{tabular}


Turpin 2005

\begin{tabular}{l|l}
\hline Methods & Randomised controlled trial. \\
\hline Participants & $\begin{array}{l}291 \text { patients } 16 \text { to } 65 \text { years old who attended Accident and Emergency (A\&E) in Sheffield } \\
\text { UK who had sustained an injury due to a road traffic accident, occupational injury or } \\
\text { assault. } 54 \text { in intervention group (34 female, mean age 40), } 46 \text { in control group (36, } \\
\text { female, mean age 37) } \\
\text { Baseline data collected within } 2 \text { weeks of A\&E admission after which patients were } \\
\text { randomised }\end{array}$ \\
\hline Interventions & $\begin{array}{l}\text { Self-help information booklet (8 pages, } 550 \text { words) entitled to 'Response to Traumatic } \\
\text { Injury', describing and normalising physiological, psychological and behavioural reac- } \\
\text { tions to traumatic injury. Intervention group patients sent a self-help booklet within } 6 \\
\text { to } 8 \text { weeks of attendance; control group sent letter without information booklet }\end{array}$ \\
\hline Outcomes & $\begin{array}{l}\text { Outcomes assessed at } 3 \text { and } 6 \text { months: } \\
\text { - PTSD: Post-Traumatic Diagnostic Scale }\end{array}$ \\
\hline Notes & $\begin{array}{l}\text { There is no indication of what the control group were told, but it is stated that "control } \\
\text { participants were offered a copy of the self-help booklet at the end of the study". Given } \\
\text { that the intervention had no positive effect, but did have some negative effects, the } \\
\text { rationale for offering the booklets is unclear }\end{array}$ \\
\hline
\end{tabular}

\section{Risk of bias}

\begin{tabular}{|c|c|c|}
\hline Item & Authors' judgement & Description \\
\hline Adequate sequence generation? & Yes & Random number tables. \\
\hline Allocation concealment? & Yes & Masked independent investigator. \\
\hline $\begin{array}{l}\text { Incomplete outcome data addressed? } \\
\text { All outcomes }\end{array}$ & No & $\begin{array}{l}\text { Reasons for losses to follow up stated. Significant differ- } \\
\text { ences in baseline characteristics between responders and } \\
\text { non-responders and in the demographic characteristics } \\
\text { (age and sex) of those lost to follow up and those with } \\
\text { complete data }\end{array}$ \\
\hline Free of selective reporting? & Yes & - \\
\hline Free of other bias? & No & $\begin{array}{l}\text { 1. There was a significantly higher proportion of assaults } \\
\text { and occupational injuries in non-responders, and of road } \\
\text { traffic accidents in responders } \\
\text { 2. Non-responders were significantly younger and more } \\
\text { likely to be male } \\
\text { 3. Only } 10 \% \text { of those eligible agreed to participate ( } 291 / \\
2818) \\
\text { 4. An administrative error required } 66 \text { of } 291 \text { partici- } \\
\text { pants who had completed baseline measures, to be re- } \\
\text { moved from the analysis }\end{array}$ \\
\hline
\end{tabular}


Turpin 2005 (Continued)

\begin{tabular}{|c|c|c|}
\hline Intention to Treat analysis? & Yes & $\begin{array}{l}\text { Main results reported are not from the intention-to-treat } \\
\text { analysis }\end{array}$ \\
\hline Blinding of outcome assessment? & Yes & $\begin{array}{l}\text { Outcomes were assessed using a self-completion postal } \\
\text { questionnaire }\end{array}$ \\
\hline
\end{tabular}

\section{Zatzick 2001}

\begin{tabular}{|c|c|}
\hline Methods & Randomised controlled trial. \\
\hline Participants & $\begin{array}{l}34 \text { road traffic accident or assault related injured patients admitted to a trauma centre in } \\
\text { California USA aged between } 14 \text { and } 65 \text { years and English speaking. } 16 \text { in intervention } \\
\text { group ( } 8 \text { female, mean age } 35.3 \text { ), } 18 \text { in control ( } 33 \% \text { female, mean age } 32.5 \text { ). }\end{array}$ \\
\hline Interventions & $\begin{array}{l}\text { Collaborative care intervention comprising a personally assigned trauma support special- } \\
\text { ist ( } 1 \text { of } 2 \text { psychiatrists or a clinical nurse specialist) who provided support to participants } \\
\text { as inpatients and subsequently as outpatients during community rehabilitation. Their } \\
\text { role was to facilitate patient-provider treatment planning, and to elicit and track patients } \\
\text { post-traumatic concerns. In addition the intervention group received a brief psycho- } \\
\text { educational intervention targeting PTSD and substance use. Trauma support specialists } \\
\text { spent on average } 91 \text { minutes over } 4 \text { months with each patient. Control participants } \\
\text { received treatment as usual }\end{array}$ \\
\hline Outcomes & $\begin{array}{l}\text { Primary outcomes measured at } 1 \text { and } 4 \text { months post-injury: } \\
\text { - PTSD using a modified form of the Post-Traumatic Stress Disorder Checklist } \\
\text { (PCL-C) } \\
\text { - Depressive symptoms using a modified form of the Centre for Epidemiological } \\
\text { Studies Depression Scale (CES-D) } \\
\text { - At-risk drinking using a single question from the Addiction Severity Index (ASI) } \\
\text { - Physical functioning using a modified form of the Physical Components } \\
\text { Summary (PCS) }\end{array}$ \\
\hline Notes & $\begin{array}{l}\text { 1. Pilot study. } \\
\text { 2. Both the intervention and control participants demonstrated high levels of PTSD and } \\
\text { depressive symptoms while in hospital } \\
\text { 3. "There were difficulties in implementing the collaborative care principles of continuous } \\
\text { case management and active sustained follow-up" and the success of doing so seems to } \\
\text { have varied, with those without insurance receiving less integrated care }\end{array}$ \\
\hline
\end{tabular}

Risk of bias

\begin{tabular}{lll}
\hline Item & Authors judgement & Description \\
\hline Adequate sequence generation? & Yes & $\begin{array}{l}\text { Computer generated algorithm using block randomisa- } \\
\text { tion with block size of } 6\end{array}$ \\
\hline Allocation concealment? & Yes & $\begin{array}{l}\text { Independent project co-ordinator conducted randomi- } \\
\text { sation. }\end{array}$
\end{tabular}


Zatzick 2001 (Continued)

\begin{tabular}{l|l|l}
\hline $\begin{array}{l}\text { Incomplete outcome data addressed? } \\
\text { All outcomes }\end{array}$ & Yes & $\begin{array}{l}\text { Reasons for losses to follow up stated. No significant } \\
\text { differences between responders and non-responders }\end{array}$ \\
\hline $\begin{array}{l}\text { Free of selective reporting? } \\
\text { Free of other bias? }\end{array}$ & No & $\begin{array}{l}\text { Effect estimates for at-risk drinking and functional lim- } \\
\text { itations not reported (stated as non significant) }\end{array}$ \\
\hline Intention to Treat analysis? & Yes & $\begin{array}{l}\text { Inpatient length of stay was significantly longer for the } \\
\text { intervention group than the control groups (10.6 versus } \\
5.6 \text { days). It is not stated that this was entered as a co- } \\
\text { variate in the analysis }\end{array}$ \\
\hline Blinding of outcome assessment? & Yes & $\begin{array}{l}\text { Research associates conducting follow-up outcome as- } \\
\text { sessment interviews were blinded to intervention status }\end{array}$ \\
\hline
\end{tabular}

$\mathrm{A} \& \mathrm{E}=$ accident and emergency

$\mathrm{CBT}=$ cognitive behavioural therapy

GDS $=$ Geriatric Depression Scale

HADS = Hospital Anxiety and Depression Scale

HRQOL = health-related quality of life

PTSD $=$ post-traumatic stress disorder

SCID $=$ Structured Clinical Interview for DSM IV

Characteristics of excluded studies [ordered by study ID]

\begin{tabular}{ll}
\hline Study & Reason for exclusion \\
\hline Allen 1996 & Treatment not prevention study as patients had not suffered from a recent injury \\
\hline Andersson 2005 & Not RCT (randomisation of 2 hospitals) \\
\hline Bisson 2004 & Treatment of PTSD \\
\hline Bordow 1979 & Not RCT (sequential allocation to groups). Same study as Porritt 1979. \\
\hline Bryant 1998 & Treatment of acute stress disorder \\
\hline Bugg (in press) & Patients only selected for trial if suffering from acute stress disorder \\
\hline Castillo 2002 & Only around 20\% of the patients have suffered an injury (patients in intensive care) \\
\hline Christakou 2007 & Treatment of ankle sprain, not prevention of disability arising from injury
\end{tabular}

Psychosocial interventions for the prevention of disability following traumatic physical injury (Review) 
(Continued)

\begin{tabular}{|c|c|}
\hline Corey 1996 & $\begin{array}{l}\text { Complex intervention including physiotherapy, work conditioning and counselling. Unable to disaggregate } \\
\text { effects of psychosocial component. Update of Mitchell } 1994 .\end{array}$ \\
\hline Craig 1998 & Not RCT \\
\hline Cramer 2007 & Not RCT \\
\hline Cupal 2001 & Treatment of anterior cruciate ligament injuries \\
\hline Drechsel-Schlund 2003 & Patients only included in trial if at high risk of Post Traumatic Stress Disorder (PTSD) \\
\hline Dunn 2003 & Not RCT \\
\hline Dunn 2004 & Outcome is behaviour change (use of seat belts) rather than disability \\
\hline Ehlers 2003 & Treatment of PTSD \\
\hline Evans 1998 & $\begin{array}{l}\text { Treatment rather than prevention of disability and cannot disaggregate those who suffered a traumatic } \\
\text { injury from participants with other disabling conditions }\end{array}$ \\
\hline Evans 2001 & $\begin{array}{l}\text { Update of Evans } 1998 \text { trial. Treatment rather than prevention of disability and cannot disaggregate those } \\
\text { who suffered a traumatic injury from participants with other disabling conditions }\end{array}$ \\
\hline Fauerbach 2002 & Outcome is not disability but reduction in pain during dressing change for a burns wound \\
\hline Fecteau 1999 & Treatment of PTSD following a motor vehicle accident \\
\hline Foa 1995 & Not RCT \\
\hline Fronek 2005 & Participants have not suffered a traumatic physical injury (staff training intervention) \\
\hline Girolami 2005 & Not RCT \\
\hline Hagglund 2007 & Outcome is not disability but rate of re-injury \\
\hline Hagsten 2006 & Intervention is physiotherapy, not psychosocial \\
\hline Hazard 2000 & Participants have not suffered a traumatic physical injury \\
\hline Jensen 2001 & $\begin{array}{l}\text { Patients have not suffered a recent injury and the intervention is complex and the psychosocial component } \\
\text { cannot be disaggregated }\end{array}$ \\
\hline Kennedy 2003 & Not RCT (control group data taken from an existing database) \\
\hline King 1999 & Not RCT (matched controls) \\
\hline Kwon 2006 & Not RCT (controls and intervention group matched) \\
\hline
\end{tabular}

Psychosocial interventions for the prevention of disability following traumatic physical injury (Review) 
(Continued)

\begin{tabular}{|c|c|}
\hline Latimer 2006 & Patients have not suffered a recent injury \\
\hline Lindstrom 1992 & The intervention is complex and the psychosocial component cannot be disaggregated \\
\hline McFarlane 2006 & Outcome is not disability but prevention of domestic violence \\
\hline Melnyk 2004 & $\begin{array}{l}\text { Unable to disaggregate those who suffered a traumatic injury from participants with other disabling } \\
\text { conditions }\end{array}$ \\
\hline Menzel 2006 & Participants have not suffered a traumatic physical injury \\
\hline Miller 1975 & Not RCT (patient choice as to which group they were assigned) \\
\hline Mitchell 1994 & $\begin{array}{l}\text { Complex intervention including physiotherapy, work conditioning and counselling. Unable to disaggregate } \\
\text { effects of psychosocial component. First report of Corey } 1996 \text { study. }\end{array}$ \\
\hline Moore 1983 & Treatment of burn wounds rather than prevention of disability \\
\hline Norman 2004 & Patients have not suffered a recent injury (chronic pelvic pain) \\
\hline Oliveira 2006 & Not RCT (alternate allocation) \\
\hline Ottosson 2007 & The intervention is complex and the psychosocial component cannot be disaggregated \\
\hline Pain 2007 & The intervention is complex and the psychosocial component cannot be disaggregated \\
\hline Phillips 2001 & The intervention is complex and the psychosocial component cannot be disaggregated \\
\hline Porritt 1979 & Not RCT (sequential allocation). Same study as Bordow 1979 \\
\hline Ross 1996 & Not RCT (alternate allocation) \\
\hline Rotem-Lehrer 2007 & Treatment of ankle sprain rather than prevention of disability \\
\hline Rottkamp 1976 & Intervention is physiotherapy rather than psychosocial \\
\hline Rowland 2006 & The intervention is complex and the psychosocial component cannot be disaggregated \\
\hline Scholes 2007 & Treatment rather than prevention as patients screened for acute stress disorder \\
\hline Scholten-Peeters 2006 & Treatment for the symptoms of whiplash \\
\hline Sirles 1991 & Participants have not suffered a traumatic physical injury \\
\hline Smith 1984 & Outcome is not disability but prevention of child abuse \\
\hline Soderstrom 2007 & Outcome is not disability but prevention of at-risk drinking \\
\hline
\end{tabular}


(Continued)

\begin{tabular}{ll}
\hline Söderlund 2007 & Treatment for the symptoms of whiplash \\
\hline Ventegodt 2004 & The intervention is complex and the psychosocial component cannot be disaggregated \\
\hline Vick 2001 & Not RCT \\
\hline Vick 2004 & Not RCT \\
\hline Wagner 2007 & Treatment for PTSD and depression \\
\hline Wise 2002 & The intervention is complex and the psychosocial component cannot be disaggregated \\
\hline Yates 2000 & Not RCT \\
\hline Zatzick 2004 & Treatment of PTSD \\
\hline Zemper 2003 & $\begin{array}{l}\text { The intervention is complex and the psychosocial component cannot be disaggregated. Not all patients } \\
\text { suffered a recent physical injury }\end{array}$ \\
\hline
\end{tabular}

PTSD $=$ post-traumatic stress disorder

$\mathrm{RCT}=$ randomised controlled trial

\section{Characteristics of studies awaiting assessment [ordered by study ID]}

\section{Humphreys 2003}

\begin{tabular}{l|l}
\hline Methods & - \\
\hline Participants & - \\
\hline Interventions & - \\
\hline Outcomes & - \\
\hline Notes & Unable to locate study. \\
\hline
\end{tabular}

McKinlay 2003

\begin{tabular}{l|l}
\hline Methods & \\
\hline Participants - \\
\hline Interventions - \\
\hline Outcomes -
\end{tabular}


McKinlay 2003 (Continued)

Notes Unable to locate study.

\section{Tecic unpublished}

\begin{tabular}{ll}
\hline Methods & RCT \\
\hline Participants & 113 severely injured trauma patients from 4 German trauma centres \\
\hline Interventions & $\begin{array}{l}\text { Short and long-term (up to } 6 \text { months post-discharge) psychotherapy compared to short-term (in hospital) psy- } \\
\text { chotherapy }\end{array}$ \\
\hline Outcomes & Depression, anxiety, PTSD \\
\hline Notes & Unpublished study \\
\hline
\end{tabular}




\section{DATA AND ANALYSES}

This review has no analyses.

\section{A P P E N D I C E S}

\section{Appendix I. Search strategies}

Cochrane Injuries Group Specialised Register (searched 5 Feb 2008)

((wound* OR injur* OR trauma OR damag*) AND (physical*)) AND (psychosocial or psycho-social OR interpersonal OR psychotherap* OR cognitive OR counsel* OR psychoanalys* OR psychodrama)

\section{CENTRAL (The Cochrane Library 2009, Issue 1)}

\#1MeSH descriptor Wounds and Injuries explode all trees \#2MeSH descriptor Spinal Cord Injuries explode all trees \#3MeSH descriptor Spinal Injuries explode all trees \#4MeSH descriptor Multiple Trauma explode all trees \#5MeSH descriptor Traumatology explode all trees \#6MeSH descriptor Injury Severity Score explode all trees \#7MeSH descriptor Abbreviated Injury Scale explode all trees \#8MeSH descriptor Trauma Severity Indices explode all trees \#9 (wound* or injur* or trauma* or damag*) near (physical*) \#10(\#1 OR \#2 OR \#3 OR \#4 OR \#5 OR \#6 OR \#7 OR \#8 OR \#9) $\# 11 \mathrm{MeSH}$ descriptor Psychotherapy explode all trees \#12MeSH descriptor Counseling explode all trees \#13(psychosocial or psycho-social) \#14(behavior* or behaviour* or family or families or cognitive or psycho*) near (therapy or therapies) \#15 (behavior* or behaviour*) near (cognitive next therap*)

\#16(interpersonal or psychotherapy* or "problem solving" or operant* or reinforcement* or biofeedback* or "social skill" or "social skills" or "cognitive behavioral" or "discussion group" or "insight oriented" or "client centered" or counsel* or insight* or paradox* or psychoanalys* or psychodrama* or "role play" or "role playing" or transactional or befriend* or mentor* or "social support") \#17(psychological) near (debrief*)

\#18(discussion) near (group*)

\#19(\#11 OR \#12 OR \#13 OR \#14 OR \#15 OR \#16 OR \#17 OR \#18)

\#20(\#10 AND \#19)

\#21MeSH descriptor Craniocerebral Trauma explode all trees

\#22 (wound* or injur* or trauma* or damag*) near (head or crani* or capitis or brain* or forebrain* or skull* or hemisphere or intracran* or orbit* or cerebr*)

\#23(\#21 OR \#22)

\#24(\#20 AND NOT \#23)

\section{MEDLINE (Ovid SP) 1950 to Jan (week 5) 2008}

1."wounds and injuries"/co, px, rh, th [Classification, Complications, Psychology, Rehabilitation, Therapy] 2.spinal cord injuries/co, px, rh, th [Classification, Complications, Psychology, Rehabilitation, Therapy] 3.spinal injuries/cl, co, rh, th, px [Classification, Complications, Rehabilitation, Therapy, Psychology] 4.multiple trauma/cl, co, px, rh, th [Classification, Complications, Psychology, Rehabilitation, Therapy] 5.exp traumatology/

6.exp injury severity score/

7.exp abbreviated injury scale/

Psychosocial interventions for the prevention of disability following traumatic physical injury (Review)

Copyright ( 2009 The Cochrane Collaboration. Published by John Wiley \& Sons, Ltd. 
8.exp trauma severity indices/

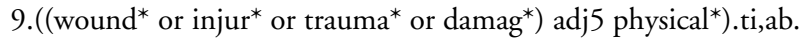

10.or/1-9

11.exp psychotherapy/

12.exp counseling/

13.(psychosocial or psycho-social).mp. [mp=title, original title, abstract, name of substance word, subject heading word]

14. ((behavior* or behaviour* or family or families or cognitive or psycho*) adj3 (therapy or therapies)).ti,ab.

15.((behavior* or behaviour*) adj3 (cognitive adj1 therap*)).ti,ab.

16.(interpersonal or psychotherap* or "problem solving" or operant* or reinforcement* or biofeedback* or "social skill" or "social skills" or "cognitive behavioral" or "discussion group" or "insight oriented" or "client centered" or counsel* or insight* or paradox* or psychoanalys* or psychodrama* or "role play" or "role playing" or transactional or befriend* or mentor* or "social support").ti,ab.

17.(psychological adj1 debrief*).ti,ab.

18.(discussion adj1 group*).ti,ab.

19.or/11-18

20.((wound* or injur* or trauma* or damag*) adj5 (head or crani* or capitis or brain* or forebrain* or skull* or hemisphere or intracran* or orbit* or cerebr*)).ti,ab.

21.exp craniocerebral traumal

22.20 or 21

23.10 and 19

24.23 not 22

25.randomi?ed.ab,ti.

26.randomized controlled trial.pt.

27.controlled clinical trial.pt.

28.placebo.ab.

29.clinical trials as topic.sh.

30.randomly.ab.

31.trial.ti.

32.25 or 26 or 27 or 28 or 29 or 30 or 31

33.humans.sh.

34.32 and 33

35.24 and 34

\section{EMBASE (Ovid SP) 1980 to (week 5) Jan 2008}

1.Injury/co, rh, si, th [Complication, Rehabilitation, Side Effect, Therapy]

2.exp Spine Injury/co, rh, si, th [Complication, Rehabilitation, Side Effect, Therapy]

3.exp traumatology/

4. ${ }^{*}$ Injury Scale/

5.((wound $\$$ or injur $\$$ or trauma $\$$ or damag $\$)$ adj5 physical $\$) . t i, a b$.

6.or/ $1-5$

7.exp psychotherapy/

8.exp counseling/

9.((psychosocial or psycho-social).ti,ab.

10.((behavior\$ or behaviour\$ or family or families or cognitive or psycho $\$$ ) adj3 (therapy or therapies)).ti,ab.

11.((behavior\$ or behaviour\$) adj3 (cognitive adj1 therap\$)).ti,ab.

12.(psychological adj1 debrief\$).ti,ab.

13. (discussion adj1 group\$).ti,ab.

14. (interpersonal or psychotherap\$ or "problem solving" or operant $\$$ or reinforcement $\$$ or biofeedback $\$$ or "social skill” or "social skills" or "cognitive behavioral" or "discussion group" or “insight oriented" or "client centered" or counsel\$ or insight $\$$ or paradox $\$$ or psychoanalys $\$$ or psychodrama $\$$ or “role play" or "role playing” or transactional or befriend $\$$ or mentor $\$$ or “social support").ti,ab.

15.or/7-14

16.6 and 15

17.exp Head Injury/ 
18.((wound $\$$ or injur\$ or trauma or damag\$) adj5 (head or crani\$ or capitis or brain $\$$ or forebrain $\$$ or skull\$ or hemisphere or intracran $\$$ or orbit $\$$ or cerebr $\$))$.ti,ab.

19.17 or 18

20.16 not 19

21.exp clinical study/

22.exp Clinical Trial/

23.randomized.ab,ti.

24.placebo.ti,ab.

25.randomly.ab,ti.

26.trial.ab,ti.

27.groups.ti,ab.

28.or/ 21-27

29.exp animal/

30.exp human/

31.29 not (29 and 30)

32.28 not 31

33.20 and 32

PsycINFO (Ovid SP) 1806 to Jan (week 5) 2008

1.Explode Wounds

2.Explode Electrical-Injuries

3.Explode Injuries

4.Explode Spinal-Cord-Injuries

5.( ((wound* or injur* or trauma* or damag*) near physical*) in AB $)$ or( (( wound* or injur* or trauma* or damag*) near physical $\left.{ }^{*}\right)$ in TI )

6.\#1 or \#2 or \#3 or \#4 or \#5

7.explode Psychotherapy

8.explode "Counseling-"

9.( ((psychosocial or psycho-social) near (therapy or therapies) $)$ in AB )or( ((psychosocial or psycho-social) near (therapy or therapies)) in TI )

10.( ((behavior* or behaviour* or family or families or cognitive or psycho*) near (therapy or therapies)) in $\mathrm{AB}$ ) or( ((behavior* or behaviour* or family or families or cognitive or psycho*) near (therapy or therapies)) in TI )

11. ( ((behavior* or behaviour*) near (cognitive therap*)) in AB )or( ((behavior* or behaviour*) near (cognitive therap*)) in TI )

12.(interpersonal or psychotherapy* or "problem solving" or operant* or reinforcement* or biofeedback* or "social skill" or "social skills" or "cognitive behavioral" or "discussion group" or "insight oriented" or "client centered" or counsel* or insight* or paradox* or psychoanalys* or psychodrama* or "role play" or "role playing" or transactional or befriend* or mentor* or "social support")near ((wound* or injur* or trauma* or damag*) near (physical*))

13. (psychological near debrief*)

14. (discussion near group*)

15.\#7 or \#8 or \#9 or \#10 or \#11 or \#12 or \#13 or \#14

16.\#6 and \#15

17.explode "Head-Injuries"

18.explode "Self-Inflicted-Wounds"

19.( ((wound* or injur* or trauma* or damag*) near (head or crani* or capitis or brain* or forebrain* or skull* or hemisphere or intracran* or orbit* or cerebr*)) in $\mathrm{AB})$ or( ((wound* or injur* or trauma* or damag*) near (head or crani* or capitis or brain* or forebrain* or skull* or hemisphere or intracran* or orbit* or cerebr*)) in TI )

$20 . \# 17$ or $\# 18$ or $\# 19$

21.\#16 not \#20

22.random*

23. (singl* or doubl* or trebl* or tripl*) near (blind* or dummy or mask ${ }^{*}$ )

24. placebo*

25.crossover

26.assign*

Psychosocial interventions for the prevention of disability following traumatic physical injury (Review)

Copyright $(2009$ The Cochrane Collaboration. Published by John Wiley \& Sons, Ltd. 
27.allocat*

28. (clin* or control* or compar* or evaluat* or prospectiv*) near (trial* or studi* or study)

29.explode placebo/

30.explode treatment effectiveness evaluation/

31.explode mental health program evaluation/

32.explode experimental design/

$33 . \# 22$ or \#23 or \#24 or \#25 or \#26 or \#27 or \#28 or \#29 or \#30 or \#31 or \#32

34.21 and 33

Controlled Trials metaRegister (www.controlled-trials.com) (Searched 5 Feb 2008)

((wound* OR injur* OR trauma OR damag*) AND (physical*)) AND (psychosocial or psycho-social OR interpersonal OR psychotherap* OR cognitive OR counsel* OR psychoanalys* OR psychodrama)

\section{AMED (Allied \& Complementary Medicine) (1985 to 6 Feb 2008)}

\#1psychotherapy or counseling

\#2psychosocial or psycho-social

\#3(behaviour or behavior or family or families or cognitive or psycho* or cognitive) next (therapy or therapies)

$\# 4$ discussion next (group or groups)

$\# 5 \# 1$ or \#2 or \#3 or \#4

\#6wound or wounds or injury or injuries or trauma

\#7traumatology

\#8physical* near damage*

\#9\#6 or \#7 or \#8

\#10\#5 and \#9

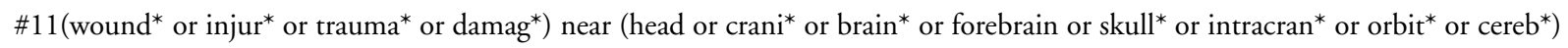
\#12\#10 not \#11

$\# 13$ (singl* ${ }^{*}$ or doubl* or trebl* or tripl*) near (blind* or dummy or mask*)

\#14(clin* or control* or compar* or evaluat* or prospectiv* or random*) near (study or studies or trial* or group* or allocate* or assign* or crossover)

\#15\#16 or \#17

$\# 16 \# 14$ and \#18

ISI Web of Science: Social Sciences Citation Index (SSCI) 1970 to Feb 2008

1. (wound* or injur* or trauma* or damag*) AND physical*) OR Spinal-Cord-Injuries

2.Psychotherapy OR Counseling OR psychosocial OR psycho-social) OR ((behavior* or behaviour* or family or families or cognitive or psycho*) AND (therapy or therapies)) OR (psychological AND debrief*) OR (discussion AND group*)

3.random* OR ((singl* or doubl* or trebl* or tripl*) AND (blind* or dummy or mask*)) OR placebo* OR crossover OR assign* OR allocat*

4.1 AND 2 AND 3

PubMed [www.ncbi.nlm.nih.gov/sites/entrez/] (searched PUBMED (from 2006 to Feb 2008)

\#1"Spinal Cord Injuries"[Mesh] OR "Wounds and Injuries"[Mesh] OR “Spinal Injuries”[Mesh] OR "Multiple Trauma”[Mesh] OR “Traumatology”[Mesh] OR “Injury Severity Score”[Mesh] OR “Abbreviated Injury Scale”[Mesh] OR “Trauma Severity Indices” [Mesh] \#2(wound* OR injur* OR trauma OR damag*) AND (physical*).TI.

$\# 3$ (wound* OR injur* OR trauma OR damag*) AND (physical*).AB.

$\# 4 \# 1$ or \#2 or \#3

\#5"Psychotherapy”[Mesh] OR “Counseling”[Mesh]

\#6(psychosocial or psycho-social OR interpersonal OR psychotherap* OR problem solving OR operant* OR reinforcement* OR biofeedback* OR social skill OR social skills OR cognitive behavioral OR discussion group OR Insight oriented OR client centered OR counsel* OR insight* OR paradox* OR psychoanalys* OR psychodrama* OR role play OR role playing OR transactional OR befriend* OR mentor* OR social support OR psychological debrief* OR discussion group*).TI.

\#7(psychosocial or psycho-social OR interpersonal OR psychotherap* OR problem solving OR operant* OR reinforcement* OR biofeedback* OR social skill OR social skills OR cognitive behavioral OR discussion group OR Insight oriented OR client centered

Psychosocial interventions for the prevention of disability following traumatic physical injury (Review) 
OR counsel* OR insight* OR paradox* OR psychoanalys* OR psychodrama* OR role play OR role playing OR transactional OR befriend* OR mentor* OR social support OR psychological debrief* OR discussion group*).AB.

\#8(behavior* OR behaviour* OR family OR families OR cognitive OR psycho*) AND (therapy OR therapies OR cognitive).TI.

\#9(behavior* OR behaviour* OR family OR families OR cognitive OR psycho*) AND (therapy OR therapies OR cognitive).AB. \#10\#5 OR \#6 OR \#7 OR \#8 OR \#9

\#11(randomised OR randomized OR randomly OR random order OR random sequence OR random allocation OR randomly allocated OR at random OR randomized controlled trial [pt] OR controlled clinical trial [pt] OR randomized controlled trials [mh]) NOT ((models, animal[mh] OR Animals[mh] OR Animal Experimentation[mh] OR Disease Models, Animal[mh] OR Animals, Laboratory[mh]) NOT (Humans[mh]))

\#12\#4 AND \#10 AND \#11

\section{H I S T O R Y}

Protocol first published: Issue 1, 2007

Review first published: Issue 4, 2009

\section{CONTRIBUTIONSOFAUTHORS}

MM and MDS were jointly responsible for reviewing papers and writing the review.

MDS was responsible for co-ordinating the overall review process, the collation of review papers and for communication with coauthors regarding their feedback.

DD was responsible for offering a third opinion on any disputes between MM and MDS regarding their reviewing of papers.

DD, US, MB, VP and PG were responsible for commenting on the protocol and the final review, and confirming the inclusion of key papers in the area.

\section{DECLARATIONS OF INTEREST}

None known.

\section{SOURCES OF SUPPORT}

\section{Internal sources}

- No sources of support supplied 


\section{External sources}

- Malcolm MacLachlan, Health Research Board (All-Ireland) Cochrane Fellowship, Ireland.

- Mary J De Silva, ESRC/MRC Interdisciplinary Post Doctoral Fellowship, UK.

- Vikram Patel, UK.

Wellcome Trust Senior Clinical Research Fellowship in Tropical Medicine.

\section{DIFFERENCES BETWEEN PROTOCOLAND REVIEW}

The following text was added:

Secondary outcomes: health care utilisation.

Searching other resources: the reference sections of all selected papers were screened for additional studies.

Because of the types of trials identified, we conducted no quantitative analysis and completed the review using a qualitative summary. Should there be trials in the future that enable a quantitative analysis, these will be performed as per the original protocol.

\section{N DEX TERMS}

\section{Medical Subject Headings (MeSH)}

Depression [prevention \& control]; Disabled Persons [* psychology]; Interpersonal Relations; Mental Disorders [* prevention \& control]; Pamphlets; Psychotherapy [ ${ }^{*}$ methods]; Randomized Controlled Trials as Topic; Self Care [methods]; Social Support; Stress Disorders, Post-Traumatic [prevention \& control]; Wounds and Injuries [* psychology]

\section{MeSH check words}

Humans 